\title{
FoxM1 is an independent poor prognostic marker and therapeutic target for advanced Middle Eastern breast cancer
}

\author{
Abdul Khalid Siraj ${ }^{1, *}$, Poyil Pratheeshkumar ${ }^{1, *}$, Sandeep Kumar Parvathareddy ${ }^{1}$, \\ Zeeshan Qadri' ${ }^{1}$, Saravanan Thangavel ${ }^{1}$, Saeeda Ahmed ${ }^{1}$, Fouad Al-Dayel ${ }^{2}$, Asma \\ Tulbah², Dahish Ajarim $^{3}$ and Khawla S. Al-Kuraya ${ }^{1}$ \\ ${ }^{1}$ Human Cancer Genomic Research, King Faisal Specialist Hospital and Research Center, Riyadh, Saudi Arabia \\ ${ }^{2}$ Department of Pathology, King Faisal Specialist Hospital and Research Centre, Riyadh, Saudi Arabia \\ ${ }^{3}$ Department of Oncology Centre, King Faisal Specialist Hospital and Research Centre, Riyadh, Saudi Arabia \\ "These authors contributed equally to this work
}

Correspondence to: Khawla S. Al-Kuraya, email: kkuraya@kfshrc.edu.sa

Keywords: breast cancer; FoxM1; thiostrepton; invasion; apoptosis

Received: October 27, $2017 \quad$ Accepted: March 02, $2018 \quad$ Published: April 03, 2018

Copyright: Siraj et al. This is an open-access article distributed under the terms of the Creative Commons Attribution License 3.0 (CC BY 3.0), which permits unrestricted use, distribution, and reproduction in any medium, provided the original author and source are credited.

\section{ABSTRACT}

Breast cancer (BC) is the most common cause of cancer-related death in females in Saudi Arabia. BC in Saudi women tend to behave more aggressively than breast cancer in the West. Therefore, identification of new molecular targets and treatment strategies are highly warranted to improve patient outcome. FoxM1 has been shown to play a critical role in pathogenesis of various malignancies. In this study, we explored the prevalence and clinical implication of FoxM1 overexpression in Saudi breast cancer. FoxM1 protein overexpression was seen in $79 \%(770 / 975)$ of BC tissues and was associated with aggressive clinical parameters such as younger age $(<30$ yrs $)(p=0.0172)$, high grade $(p<0.0001)$, mucinous histology $(p<0.0001)$ and triple negative phenotype $(p<0.0001)$. Overexpression of FoxM1 was significantly associated with activated AKT $(p<0.0001)$, Ki67 expression $(p<0.0001)$, VEGF $(p<$ $0.0001)$, MMP-9 $(p<0.0001)$, XIAP $(p<0.0001)$ and Bcl-XL $(p=0.0300)$. Importantly, FoxM1 overexpression is found to be an independent prognostic marker in multivariate analysis in advanced stage (Stage III and IV) breast cancer $(p=0.0298)$. In vitro data using BC cell lines showed that down-regulation of FoxM1 using specific inhibitor, thiostrepton or siRNA inhibited cell migration, invasion and angiogenesis. In addition, treatment of BC cell lines with thiostrepton resulted in inhibition of proliferation and induction of apoptosis in a dose-dependent manner. In vivo, thiostrepton treatment regressed MDA-MB-231 cells generated xenografts via down-regulation of FoxM1 and its downstream targets. Our results suggest that FoxM1 may be a potential therapeutic target for the treatment of aggressive breast cancers.

\section{INTRODUCTION}

Breast cancer (BC) is the most common malignancy among females and second leading cause of cancer deaths worldwide [1]. Generally, incidence of BC increases with age and approximately $40 \%$ of all patients with $\mathrm{BC}$ experience a relapse, of which $10-20 \%$ are local and $60-70 \%$ are distant metastases $[2,3]$. Unlike Western population, BC is more aggressive in Saudi Arabia, presenting at an early age and more advanced stage with higher morbidity and mortality $[4,5]$. The poor outcomes in breast cancer are mainly due to the lack of successful therapeutic options following development of resistance to standard therapies (ie, chemotherapy and radiotherapy) and metastatic disease [6]. Identification of new targeted therapy that allows progress in the management of aggressive breast cancer and improves survival is warranted.

Forkhead box M1 (FoxM1) is a transcription factor from FOX protein family which plays an important role 
in cell proliferation, cell cycle progression, invasion, and metastasis [7-16]. Previous studies demonstrated that elevated FoxM1 expression is found in a variety of cancers, including breast, ovarian, colon, liver, pancreatic, gastric and other cancers [14, 15, 17-21]. Moreover, overexpression of FoxM1 is correlated with a clinically aggressive, drug-resistant, cancer phenotype with poor prognosis [22-25]. However, the clinical relevance of FoxM1 expression has not been investigated in breast cancer in Saudi Arabia, a country with a particularly more aggressive breast cancer and an unusually young age of onset.

The aim of this study is to determine the expression level of FoxM1 in Middle Eastern breast cancer and to examine its association with clinico-pathologic variables as well as to assess its utility as a prognostic indicator. In this study, we have first investigated in detail the expression of FoxM1 in a large cohort of more than 1000 Middle Eastern BC samples using tissue microarray and correlated the data with various clinical and molecular parameters. Our findings indeed confirm the clinical significance of FoxM1 in aggressive Middle Eastern breast cancer. In vitro studies were performed using either thiostrepton, a specific FoxM1 inhibitor with proteasomal inhibition activity or siRNA specifically targeting FoxM1 transcript on BC cell lines, to identify FoxM1 as a potential therapeutic target. We demonstrated that down regulation of FoxM1 inhibited cell proliferation, migration, invasion and angiogenesis of $\mathrm{BC}$ cell lines. Finally, we have correlated our in vitro findings by generating BC cell-xenograft on nude mice and targeted them with thiostrepton. The results presented here help to identify significant role of FoxM1 overexpression in advanced Middle Eastern BC and their use as prognostic marker and therapeutic target in $\mathrm{BC}$.

\section{RESULTS}

\section{Expression of FoxM1 by immunohistochemistry (IHC) and correlation with clinico-pathological data}

We first sought to determine over-expression of FoxM1 in a cohort of clinical BC samples by IHC in a tissue microarray format. Using a TMA of 1009 samples, FoxM1 staining was interpretable in 975 spots and FoxM1 was found to be over-expressed in 79\% (770/975) of cases and was found to be significantly associated with younger age $(<30$ years) $(p=0.0172)$, poorly differentiated BC $(p$ $<0.0001)$, mucinous histology $(p<0.0001)$ and TNBC ( $\mathrm{p}$ $<0.0001$ ), however, there was no association with tumor size, nodal involvement and metastasis (Table 1). At the molecular level, FoxM1 over-expression was significantly associated with XIAP $(p<0.0001)$, p-AKT $(p=0.0001)$, Bcl-xL $(p=0.0300)$, VEGF $(p<0.0001)$, MMP-9 $(p<$ $0.0001)$ and proliferative marker, $\operatorname{Ki} 67(p<0.0001)$ over- expression (Table 1 and Figure 1). BC patients showing FoxM1 over-expression showed poor overall survival compared to cases not expressing this protein but this difference did not reach statistical significance $(p=$ 0.1044) (Table 1). However, when we examined late stage (Stage III and IV) BC cases in our cohort of samples, our data showed that FoxM1 over-expression was $76.8 \%$ and significantly associated with younger age $(p=0.0033)$, poorly differentiated tumors $(p<0.0001)$, mucinous histology $(p=0.0003)$ and TNBC $(p=0.0008)$ as well as a poor overall 5 year survival $(p=0.0033$ ) (Table 2 and Supplementary Figure 1). On multivariate analysis using the Cox proportional hazards model, FoxM1 overexpressing cases in late stage demonstrated significant poor survival when adjusted for age, histology, tumor grade and TNBC (hazard ratio, 1.82; 95\% confidence interval [95\% CI], 1.06-3.37 [ $p=0.0298]$ ) (Supplementary Table 2).

\section{Inhibition of FoxM1 in BC cells decreased invasion, migration and angiogenesis}

It is known that in addition of increasing proliferation of cancer cells [26-28], FoxM1 plays a major role in increasing the capability of cancer cells to invade surrounding tissues and migrate to other regions thereby increasing the metastatic potential in various cancers [2831]. Therefore, targeting FoxM1 expression can lead to inhibition of these invasion and migration properties of cancer cells. Our clinico-pathological data showed that FoxM1 over-expression was significantly associated with VEGF and MMP-9 expression, proteins implicated in tumor angiogenesis and extracellular matrix degradation respectively, thereby allowing cancer cells to invade and migrate to surrounding tissue $[32,33]$. Therefore, we sought to determine whether FoxM1 down-regulation using thiostrepton, a specific inhibitor of FoxM1 with additional proteasomal activity [34] affects the expression of VEGF, MMP-9 and MMP-2 that plays an important role in invasion, migration and angiogenesis. In our study, treatment of thiostrepton markedly down-regulated the expressions of FoxM1, VEGF, MMP-9 and MMP-2 in both BC cells, CAL-120 and MDA-MB-231 (Figure 2A). Similar results were observed by immunofluorescence where down-regulation of FoxM1 using thiostrepton decreases VEGF expression in BC cells (Figure 2B). This data was further confirmed by using specific FoxM1 siRNA knockdown in BC cells showing similar results (Figure 2C and 2D).

To investigate whether down regulation of FoxM1 plays a role in inhibiting invasion and migration, $\mathrm{BC}$ cell lines were treated with different doses of thiostrepton. Interestingly, inhibition of FoxM1 using thiostrepton significantly decreased invasion (Figure 2E and $2 \mathrm{~F}$ ) and migration (Figure 2G) of $\mathrm{BC}$ cells. These data suggest that thiostrepton treatment of $\mathrm{BC}$ cells decreases the 
Table 1: Correlation of FoxM1 with clinico-pathological parameters in breast cancer

\begin{tabular}{|c|c|c|c|c|c|c|c|}
\hline & \multicolumn{2}{|c|}{ Total } & \multicolumn{2}{|c|}{ High } & \multicolumn{2}{|c|}{ Low } & \multirow[t]{2}{*}{$P$ value } \\
\hline & $N$ & $\%$ & $N$ & $\%$ & $N$ & $\%$ & \\
\hline Total Number of Cases & 975 & & 770 & 79.0 & 205 & 21.0 & \\
\hline \multicolumn{8}{|l|}{ Age Groups } \\
\hline$<30$ & 54 & 5.5 & 49 & 90.7 & 5 & 9.3 & 0.0172 \\
\hline 30 & 921 & 94.5 & 721 & 78.3 & 200 & 21.7 & \\
\hline \multicolumn{8}{|l|}{ Tumor size } \\
\hline $\mathrm{T} 1$ & 207 & 21.7 & 168 & 81.2 & 39 & 18.8 & 0.6978 \\
\hline $\mathrm{T} 2$ & 481 & 50.5 & 380 & 79.0 & 101 & 21.0 & \\
\hline $\mathrm{T} 3$ & 141 & 14.8 & 107 & 75.9 & 34 & 24.1 & \\
\hline $\mathrm{T} 4$ & 124 & 13.0 & 97 & 78.2 & 27 & 21.8 & \\
\hline \multicolumn{8}{|l|}{ Lymph Nodes } \\
\hline No & 302 & 33.1 & 243 & 80.5 & 59 & 19.5 & 0.2017 \\
\hline N1 & 295 & 32.3 & 235 & 79.7 & 60 & 20.3 & \\
\hline $\mathrm{N} 2$ & 189 & 20.7 & 138 & 73.0 & 51 & 27.0 & \\
\hline $\mathrm{N} 3$ & 127 & 13.9 & 103 & 81.1 & 24 & 18.9 & \\
\hline \multicolumn{8}{|l|}{ Metastasis } \\
\hline M0 & 785 & 89.8 & 620 & 79.0 & 165 & 21.0 & 0.5778 \\
\hline M1 & 89 & 10.2 & 68 & 76.4 & 21 & 23.6 & \\
\hline \multicolumn{8}{|l|}{ Tumour Stage } \\
\hline I & 75 & 8.8 & 64 & 85.3 & 11 & 14.7 & 0.3992 \\
\hline II & 371 & 43.8 & 292 & 78.7 & 79 & 21.3 & \\
\hline III & 312 & 36.8 & 240 & 76.9 & 72 & 23.1 & \\
\hline IV & 89 & 10.5 & 68 & 76.4 & 21 & 23.6 & \\
\hline \multicolumn{8}{|l|}{ Recurrence } \\
\hline Yes & 253 & 29.5 & 216 & 85.4 & 37 & 14.6 & 0.0028 \\
\hline No & 605 & 70.5 & 463 & 76.5 & 142 & 23.5 & \\
\hline \multicolumn{8}{|l|}{ Extra Nodal Ext. } \\
\hline Yes & 266 & 33.2 & 210 & 79.0 & 56 & 21.0 & 0.9438 \\
\hline No & 536 & 66.8 & 422 & 78.7 & 114 & 21.3 & \\
\hline \multicolumn{8}{|l|}{ LVI } \\
\hline Yes & 359 & 41.4 & 280 & 78.0 & 79 & 22.0 & 0.8587 \\
\hline No & 507 & 58.6 & 398 & 78.5 & 109 & 21.5 & \\
\hline \multicolumn{8}{|l|}{ Histological Grade } \\
\hline Well differentiated & 76 & 7.9 & 64 & 85.3 & 11 & 14.7 & $<0.0001$ \\
\hline Moderately differentiated & 495 & 51.3 & 370 & 74.7 & 125 & 25.3 & \\
\hline Poorly differentiated & 393 & 40.8 & 355 & 90.3 & 38 & 9.7 & \\
\hline \multicolumn{8}{|l|}{ Histology } \\
\hline Infiltrating Ductal Carcinoma & 888 & 93.8 & 712 & 80.2 & 176 & 19.8 & $<0.0001$ \\
\hline Infiltrating Lobular & 43 & 4.5 & 22 & 51.2 & 21 & 48.8 & \\
\hline Mucinous $\mathrm{Ca}$ & 16 & 1.7 & 15 & 93.8 & 1 & 6.2 & \\
\hline \multicolumn{8}{|l|}{ Triple Negative } \\
\hline No & 826 & 85.1 & 633 & 76.6 & 193 & 23.4 & $<0.0001$ \\
\hline Yes & 145 & 14.9 & 135 & 93.1 & 10 & 6.9 & \\
\hline \multicolumn{8}{|l|}{ Ki-67 } \\
\hline Above 30 & 619 & 64.7 & 555 & 89.7 & 64 & 10.3 & $<0.0001$ \\
\hline Below $=30$ & 337 & 35.3 & 205 & 60.8 & 132 & 39.2 & \\
\hline
\end{tabular}




\begin{tabular}{|c|c|c|c|c|c|c|c|}
\hline Above 85 & 283 & 29.8 & 256 & 90.5 & 27 & 9.5 & $<0.0001$ \\
\hline Below $=85$ & 667 & 70.2 & 503 & 75.4 & 164 & 24.6 & \\
\hline \multicolumn{8}{|c|}{ phos_AKT (473) } \\
\hline Negative & 729 & 77.5 & 558 & 76.5 & 171 & 23.5 & 0.0001 \\
\hline Positive & 212 & 22.5 & 187 & 88.2 & 25 & 11.8 & \\
\hline \multicolumn{8}{|l|}{ MMP-9 } \\
\hline Above 50 & 670 & 72.0 & 584 & 87.2 & 86 & 12.8 & $<0.0001$ \\
\hline Below $=50$ & 261 & 28.0 & 151 & 57.8 & 110 & 42.2 & \\
\hline \multicolumn{8}{|l|}{ VEGFA } \\
\hline Above 100 & 709 & 78.7 & 589 & 83.1 & 120 & 16.9 & $<0.0001$ \\
\hline Below $=100$ & 192 & 21.3 & 132 & 68.7 & 60 & 31.3 & \\
\hline \multicolumn{8}{|l|}{ BCL-XI } \\
\hline Above 220 & 268 & 28.97 & 228 & 85.07 & 40 & 14.93 & 0.0300 \\
\hline Below $=220$ & 657 & 71.03 & 519 & 79.00 & 138 & 21.00 & \\
\hline \multicolumn{8}{|l|}{ Survival } \\
\hline OS 5 Years & & & & 78.2 & & 86.5 & 0.1044 \\
\hline
\end{tabular}

ability of cancer cells to spread to local and surrounding areas due to down-regulation of FoxM1. To determine whether FoxM1 transcriptionally activates VEGF in our model, we performed ChIP analysis. Previous reports indicated the presence of two putative FoxM1 binding regions in the VEGF promoter [33]. As shown in Figure $2 \mathrm{H}$, ChIP analysis demonstrated that FoxM1 binds to VEGF promoters at both sites, F1 (-1635-1420) and F2 (-634-442) in BC cells. Interestingly, the degree of FoxM1 binding to VEGF promoter at both sites was decreased after thiostrepton treatment in a dose dependent manner (Figure 2H and 2I).

\section{Inhibition of FoxM1 in BC cells decreased HUVECs chemotactic migration, invasion and tube formation}

Our data showed that FoxM1 over-expression was significantly associated with VEGF in BC patient samples and inhibition of FoxM1 drastically downregulated VEGF expression in BC cells. VEGF plays an important role during neo-angiogenesis through its mitogenic effect on endothelial cells [35]. Therefore, we sought to investigate whether down-regulation of FoxM1 in BC cells could inhibit chemotactic migration, invasion, and tube formation of HUVECs. For this, BC cell lines were treated with thiostrepton or FoxM1 siRNA for indicated doses. After treatment, conditioned media was collected and used for HUVECs chemotactic migration, invasion, and tube formation experiments.

Effect of FoxM1 downregulation on the chemotactic motility of HUVECs is shown in Figure 3A-3C. HUVECs migrated into the clear area when stimulated with conditioned media (source of VEGF) of BC cells whereas, less migration was observed in wells treated with conditioned media from thiostrepton (Figure 3A and 3B) or FoxM1 siRNA treated (Figure 3C) BC cells. HUVECs showed a high invasive property through the collagen matrix when treated with conditioned media from BC cells (Figure 3D-3F). Treatment with conditioned media from thiostrepton (Figure 3D and 3E) or FoxM1 siRNA treated (Figure 3F) BC cells caused less invasion of HUVECs in a dose dependent manner.

The tubular formation of endothelial cells is also a key step of angiogenesis [35]. Incubation of HUVECs with conditioned media (source of VEGF) of BC cells resulted in the formation of elongated and tube like structures which were effectively reduced by conditioned media from thiostrepton (Figure $3 \mathrm{G}$ and $3 \mathrm{H}$ ) or FoxM1 siRNA (Figure 3I) treated BC cells. To further confirm these observations, we determined the secreted levels of VEGF by ELISA experiment in thiostrepton or FoxM1 siRNA treated BC cells (Supplementary Figure 2A2B). Decreased levels of VEGF was observed in a dose dependent manner in thiostrepton (Supplementary Figure 2A) or FoxM1 siRNA (Supplementary Figure 2B) treated $\mathrm{BC}$ cells. Together, these findings suggest that inhibition of FoxM1 can significantly suppresses endothelial cell invasion, migration and angiogenesis by down-regulating VEGF.

\section{Thiostrepton treatment of $\mathrm{BC}$ cells caused inhibition of cell viability and induction of caspase-dependent apoptosis}

After analyzing the clinical data, we sought to determine whether targeting FoxM1 expression in BC cells can be used as a viable therapeutic strategy to inhibit cell viability and induce apoptosis in addition to inhibition of invasion and migration. We therefore treated $\mathrm{BC}$ cell lines, CAL-120 and MDA-MB-231, with increasing doses of thiostrepton for 48 hours and investigated cell 
Table 2: Correlation of FoxM1 with clinico-pathological parameters in late stage breast cancer (Stage III+IV)

\begin{tabular}{|c|c|c|c|c|c|c|c|}
\hline & \multicolumn{2}{|c|}{ Total } & \multicolumn{2}{|c|}{ High } & \multicolumn{2}{|c|}{ Low } & \multirow[t]{2}{*}{$P$ value } \\
\hline & $N$ & $\%$ & $N$ & $\%$ & $N$ & $\%$ & \\
\hline Total Number of Cases & 401 & & 308 & 76.8 & 93 & 23.2 & \\
\hline \multicolumn{8}{|l|}{ Age Groups } \\
\hline$<30$ & 16 & 4.0 & 16 & 100.0 & 0 & 0.0 & 0.0033 \\
\hline 30 & 385 & 96.0 & 292 & 75.8 & 93 & 24.2 & \\
\hline \multicolumn{8}{|l|}{ Tumor size } \\
\hline $\mathrm{T} 1$ & 39 & 9.8 & 29 & 74.4 & 10 & 25.6 & 0.9715 \\
\hline $\mathrm{T} 2$ & 151 & 37.7 & 117 & 77.5 & 34 & 22.5 & \\
\hline $\mathrm{T} 3$ & 106 & 26.5 & 81 & 76.4 & 25 & 23.6 & \\
\hline $\mathrm{T} 4$ & 104 & 26.0 & 81 & 77.9 & 23 & 22.1 & \\
\hline \multicolumn{8}{|l|}{ Lymph Nodes } \\
\hline N0 & 23 & 6.1 & 20 & 87.0 & 3 & 13.0 & 0.1827 \\
\hline N1 & 81 & 21.5 & 63 & 77.8 & 18 & 22.2 & \\
\hline $\mathrm{N} 2$ & 168 & 44.4 & 122 & 72.6 & 46 & 27.4 & \\
\hline N3 & 106 & 28.0 & 87 & 82.1 & 19 & 17.9 & \\
\hline \multicolumn{8}{|l|}{ Metastasis } \\
\hline M0 & 312 & 77.8 & 240 & 76.9 & 72 & 23.1 & 0.9187 \\
\hline M1 & 89 & 22.2 & 68 & 76.4 & 21 & 23.6 & \\
\hline \multicolumn{8}{|l|}{ Tumour Stage } \\
\hline III & 312 & 77.8 & 240 & 76.9 & 72 & 23.1 & 0.9187 \\
\hline IV & 89 & 22.2 & 68 & 76.4 & 21 & 23.6 & \\
\hline \multicolumn{8}{|l|}{ Extra Nodal Ext. } \\
\hline Yes & 190 & 50.8 & 152 & 80.0 & 38 & 20.0 & 0.2007 \\
\hline No & 184 & 49.2 & 137 & 74.5 & 47 & 25.5 & \\
\hline \multicolumn{8}{|l|}{ LVI } \\
\hline Yes & 213 & 57.9 & 170 & 79.8 & 43 & 20.2 & 0.2045 \\
\hline No & 155 & 42.1 & 115 & 74.2 & 40 & 25.8 & \\
\hline \multicolumn{8}{|l|}{ Recurrence } \\
\hline Yes & 144 & 39.4 & 128 & 88.9 & 16 & 11.1 & $<0.0001$ \\
\hline No & 221 & 60.6 & 155 & 70.1 & 66 & 29.9 & \\
\hline \multicolumn{8}{|l|}{ Histological Grade } \\
\hline Well differentiated & 21 & 5.3 & 8 & 38.1 & 13 & 61.9 & $<0.0001$ \\
\hline Moderately differentiated & 205 & 51.5 & 145 & 70.7 & 60 & 29.3 & \\
\hline Poorly differentiated & 172 & 43.2 & 154 & 89.5 & 18 & 10.5 & \\
\hline \multicolumn{8}{|l|}{ Histology } \\
\hline Infiltrating Ductal Carcinoma & 372 & 94.2 & 294 & 79.0 & 78 & 21.0 & 0.0003 \\
\hline Infiltrating Lobular & 21 & 5.3 & 8 & 38.1 & 13 & 61.9 & \\
\hline Mucinous Ca & 2 & 0.5 & 2 & 100.0 & 0 & 0 & \\
\hline \multicolumn{8}{|l|}{ Triple Negative } \\
\hline No & 336 & 84.4 & 249 & 74.1 & 87 & 25.9 & 0.0008 \\
\hline Yes & 62 & 15.6 & 57 & 91.9 & 5 & 8.1 & \\
\hline \multicolumn{8}{|l|}{ Ki-67 IHC } \\
\hline Above 30 & 261 & 66.6 & 236 & 90.4 & 25 & 9.6 & $<0.0001$ \\
\hline Below $=30$ & 131 & 33.4 & 68 & 51.9 & 63 & 48.1 & \\
\hline
\end{tabular}




\begin{tabular}{|c|c|c|c|c|c|c|c|}
\hline XIAP & & & & & & & \\
\hline Above 85 & 123 & 31.5 & 110 & 89.4 & 13 & 10.6 & $<0.0001$ \\
\hline Below $=85$ & 268 & 68.5 & 192 & 71.6 & 76 & 28.4 & \\
\hline \multicolumn{8}{|c|}{ phos_AKT (473) } \\
\hline Negative & 278 & 72.2 & 203 & 73.0 & 75 & 27.0 & 0.0005 \\
\hline Positive & 107 & 27.8 & 95 & 88.8 & 12 & 11.2 & \\
\hline \multicolumn{8}{|l|}{ MMP-9 } \\
\hline Above 50 & 266 & 69.8 & 228 & 85.7 & 38 & 14.3 & $<0.0001$ \\
\hline Below $=50$ & 115 & 30.2 & 64 & 55.6 & 51 & 44.4 & \\
\hline \multicolumn{8}{|l|}{ VEGFA } \\
\hline Above 100 & 279 & 74.0 & 229 & 82.1 & 50 & 17.9 & 0.0017 \\
\hline Below $=100$ & 98 & 26.0 & 65 & 66.3 & 33 & 33.7 & \\
\hline \multicolumn{8}{|l|}{ Survival } \\
\hline OS 5 Years & & & & 60.2 & & 83.0 & 0.0033 \\
\hline
\end{tabular}

viability by MTT assay. As shown in Figure 4A, there was a significant $(p<0.05)$ dose-dependent inhibition of cell viability in both the cell lines. Using doses of 5 and 10 $\mu \mathrm{M}$ thiostrepton and 48 hours' time point, the rest of the experiments were performed. We next examined colony formation in $\mathrm{BC}$ cells following treatment with 5 and 10 $\mu \mathrm{M}$ thiostrepton. Following treatment with thiostrepton, cells were plated in agarose gel and allowed to grow at $37^{\circ} \mathrm{C}$ for 4 weeks following which cells were stained and visualized on an inverted microscope. $\mathrm{BC}$ cells treated with thiostrepton lost their ability to form colonies in both the cell lines (Figure 4B and 4C).

We wanted to determine whether inhibition of cell viability was due to cell cycle arrest or apoptosis. For this reason, we treated both $\mathrm{BC}$ cells with 5 and $10 \mu \mathrm{M}$ thiostrepton for 48 hours and analyzed the cells for cell cycle by flow cytometry. Our data showed that there was a decrease in the G1 and G2 fraction with concurrent shift of cells in Sub-G1 fraction depicting apoptosis [36] (Figure 4D). We also analyzed cell death by Live Dead assay following treatment with thiostrepton to confirm that cells following treatment were actually dying and the decreased cell counts were not due to cell inhibition (Figure 4E). Finally, to confirm apoptosis in thiostrepton treated BC cells, we stained CAL-120 and MDAMB-231 cells with annexin V and Propidium iodide following treatment with 5 and $10 \mu \mathrm{M}$ thiostrepton for 48 hours and analyzed by flow cytometry. As shown in

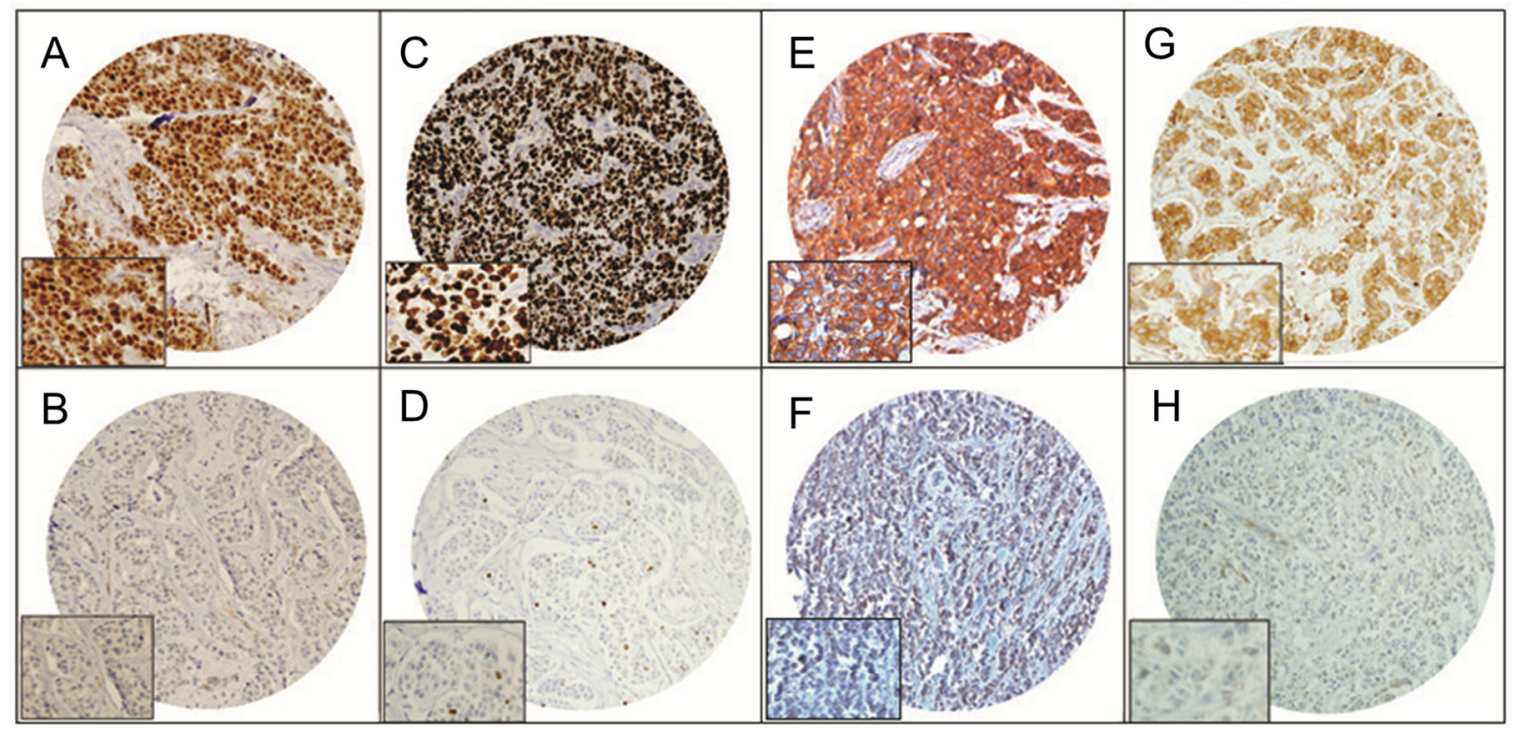

Figure 1: Tissue microarray based immunohistochemistry analysis of FoxM1, Ki-67, VEGF and MMP-9 in breast cancer (BC) patients. BC TMA spots showing overexpression of FoxM1 (A), Ki-67 (C), VEGF (E), and MMP-9 (G). In contrast, another set of TMA spots showing reduced expression of FoxM1 (B), Ki-67 (D), VEGF (F), and MMP-9 (H). 20 X/0.70 objective on an Olympus BX 51 microscope. (Olympus America Inc, Center Valley, PA, USA) with the inset showing a 40X 0.85 aperture magnified view of the same TMA spot. 
Figure $4 \mathrm{~F}-4 \mathrm{G}$, there was an increase in apoptotic cells following treatment with thiostrepton in both the cell lines confirming that these cell death was due to apoptosis.

Once the data generated confirmed that $\mathrm{BC}$ cells treated with thiostrepton were actually undergoing apoptosis, we were interested in identifying the apoptotic pathway that was being activated by thiostrepton in inducing apoptosis. Our clinico-pathological data showed a significant association between FoxM1 over-expression and activated AKT. It has been previously shown that phosphorylation of AKT inhibits apoptosis via activation of Bad [37]. We therefore examined the activation status of AKT and Bad in BC cells following treatment with 5 and $10 \mu \mathrm{M}$ thiostrepton for 48 hours. As shown in Figure $5 \mathrm{~A}$, there was inactivation of AKT and Bad in thiostrepton treated $\mathrm{BC}$ cells as determined by Western blotting. Once Bad protein is inactivated, the apoptotic signal reaches the mitochondria and causes down-regulation of anti-
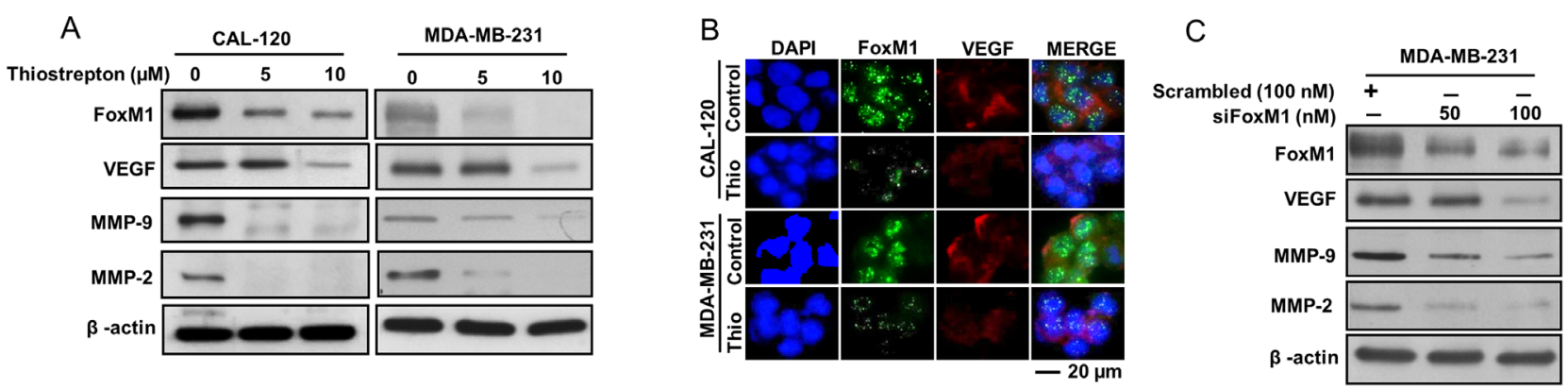

D

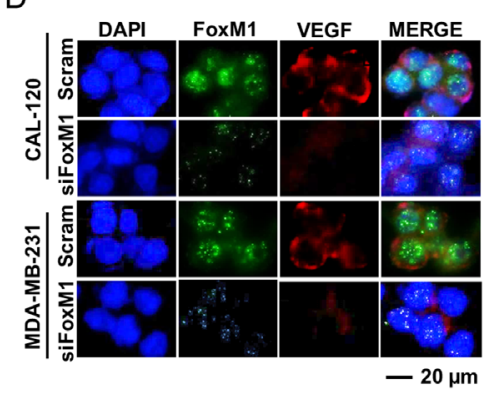

G

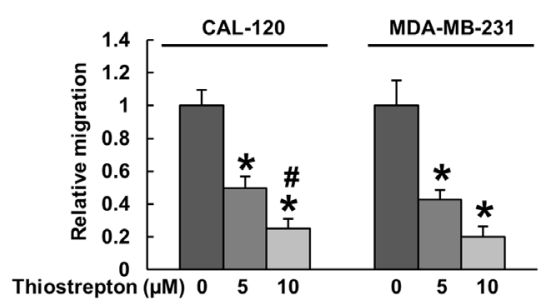

E

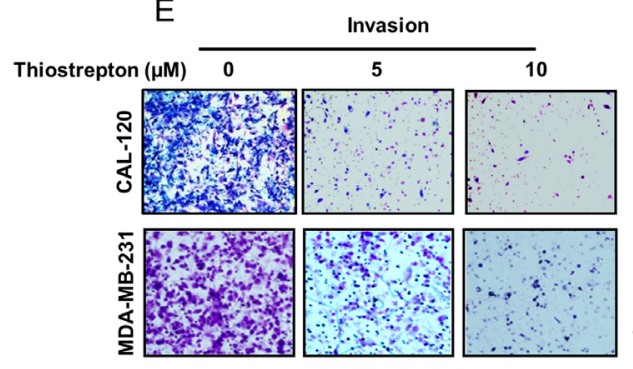

$\mathrm{H}$

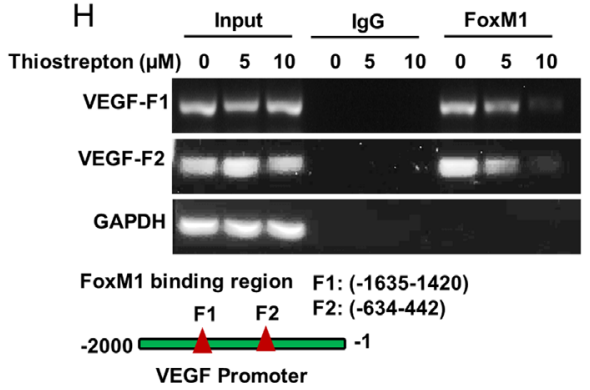

$\mathrm{F}$

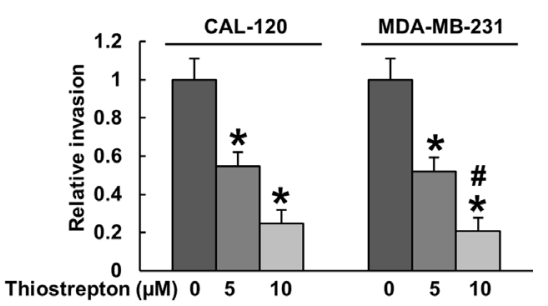

1

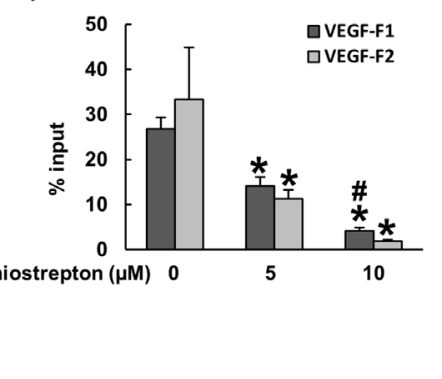

Figure 2: Inhibition of FoxM1 in BC cells decreased invasion, migration and angiogenesis. (A) Thiostrepton inhibits the expression of FoxM1, VEGF, MMP-9 and MMP-2 in BC cells. CAL-120 and MDA-MB-231 cells were treated with 5 and 10 mM thiostrepton for 48 hours. After cell lysis, equal amounts of proteins were separated on SDS-PAGE, and immunoblotted with antibodies against FoxM1, VEGF, MMP-9, MMP-2 and Beta-actin as indicated. (B) Representative images of fluorescence immunostaining for FoxM1 and VEGF in BC cells after treatment with thiostrepton. (C) FoxM1 siRNA transfection down-regulated expression of FoxM1, VEGF, MMP-9 and MMP-2 in BC cells. MDA-MB-231 cells were transfected with scrambled siRNA (100 nM) and FoxM1 siRNA(50 nM and $100 \mathrm{nM}$ ) with Lipofectamine 2000. After transfection, cells were lysed and equal amounts of proteins were separated by SDS-PAGE, and immunoblotted with antibodies against FoxM1, VEGF, MMP-9, MMP-2 and Beta-actin as indicated. (D) Representative images of fluorescence immunostaining for FoxM1 and VEGF in BC cells after post-transfection with FoxM1 siRNA. (E-G) Invasion-migration assays were performed using CAL-120 and MDA-MB-231 cells treated with 5 and $10 \mu \mathrm{M}$ thiostrepton for 48 hours as described in Materials and Methods. (H-I) FoxM1 binding to VEGF promoter. For the ChIP assay, the FoxM1 binding regions on VEGF promoter were identified. MDA-MB-231 cells were treated with and without thiostrepton $(5$ and $10 \mu \mathrm{m})$ for $24 \mathrm{~h}$, fixed with formaldehyde, and cross-linked, and then chromatin was isolated. The chromatin was immunoprecipitated (IP) with an anti-FoxM1 antibody or control mouse IgG. The FoxM1 binding to the VEGF promoters was analyzed by regular PCR (H) or quantitative real time PCR (I) with a primer specific for the FoxM1 binding regions in VEGF promoter. The data represent the percent input and are normalized to each control. GAPDH was used as a loading control. Data presented in bar graphs are the mean $\pm \mathrm{SD}$ of three independent experiments. ${ }^{*}$ and ${ }^{\#}$ indicate statistically significant differences compared to control without treatment or thiostrepton $(5 \mu \mathrm{M})$ treatment, respectively with $p<0.05$. 
apoptotic proteins, Bcl-2 and Bcl-xL. Our data showed that there was down-regulation of expression of Bcl-2 and $\mathrm{Bcl}-\mathrm{xL}$ following treatment with thiostrepton (Figure $5 \mathrm{~A})$. After the apoptotic signal reaches the mitochondria, it elicits its disruptive function leading to change in the mitochondrial membrane potential leading to damage. Therefore, we investigated the changes in membrane potential of the mitochondria following treatment with thiostrepton. We found there was increased mitochondrial damage after thiostrepton treatment in both cell lines studied as depicted by an increase in green stained cells (apoptotic cells) as compared to red stained cells (normal cancer cells) (Figure 5B). This data confirmed that the mitochondrion was indeed getting damaged following down-regulation of anti-apoptotic proteins, Bcl-2 and Bcl-xL, as a consequence of FoxM1 down-regulation. Once the mitochondrion is damaged, there is release of cytochrome c into cytosol thereby leading to activation and cleavage of caspase-9. To ascertain these findings, we treated $\mathrm{BC}$ cells with 5 and $10 \mu \mathrm{M}$ thiostrepton for 48 hours and isolated cytosolic as well as mitochondrial extracts. As shown in Figure 5C, there was decrease in expression of cytochrome $\mathrm{c}$ in mitochondrial extracts following treatment with thiostrepton with concurrent increase of cytochrome $\mathrm{c}$ in the cytosolic compartment confirming mitochondrial damage and cytochrome $\mathrm{c}$ release. In order for the intrinsic apoptotic pathway to be efficiently activated, Inhibitor of Apoptosis Proteins (IAPs) also needs to be down regulated following treatment with thiostrepton. Therefore, we examined expression of IAPs; XIAP, cIAP1 and survivin in BC cells following treatment with 5 and $10 \mu \mathrm{M}$ thiostrepton for 48 hours. There was down-regulation of the IAPs in both cell lines examined (Figure 5D).

Once cytochrome c is released into cytosol and down-regulation of IAPs, there is activation and cleavage
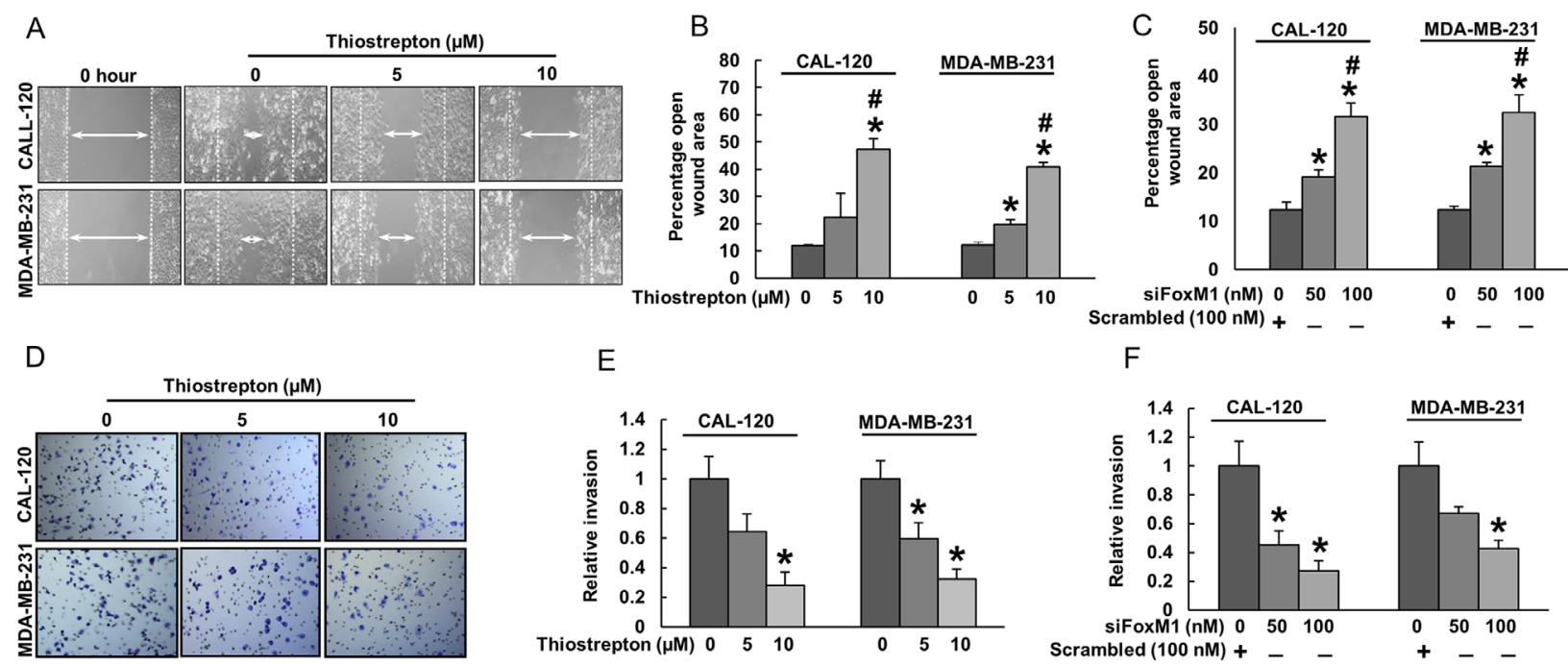

$\mathrm{F}$
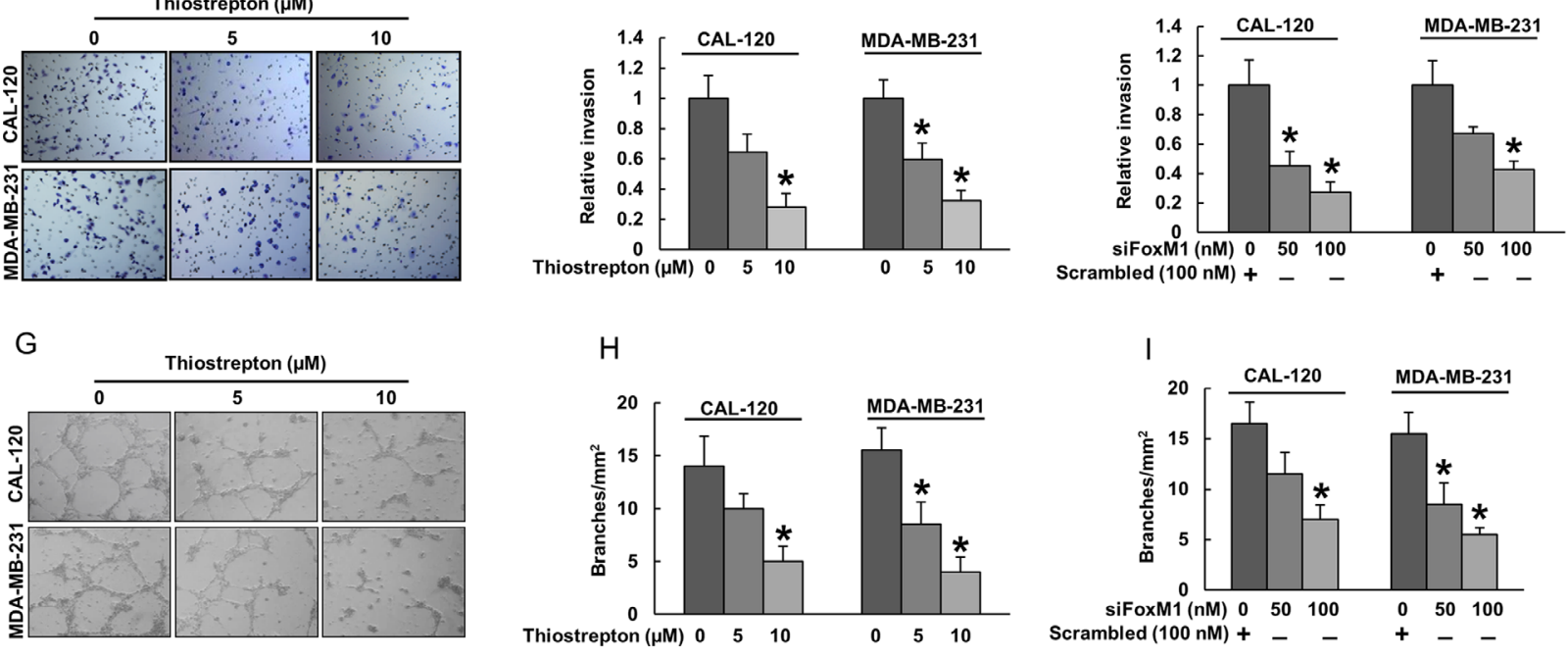

Figure 3: Inhibition of FoxM1 in BC cells decreased HUVECs chemotactic migration, invasion, and tube formation. (A-C) Inhibition of FoxM1 decreased HUVECs migration. HUVECs were grown into wells of collagen coated 24 well plate dishes to $100 \%$ confluence. Cells were starved to inactivate cell proliferation and then wounded by $200 \mu \mathrm{l}$ pipette tips. Cells were treated with conditioned media from BC cells treated with thiostrepton or FoxM1 siRNA. Images were taken at $0 \mathrm{~h}$ and $24 \mathrm{~h}$ following wounding. The wound area was measured using Image J software, and data was expressed as percentage of open wound area calculated by dividing migrated distance by scratched distance. (D-F) Inhibition of FoxM1 decreased HUVECs invasion. HUVECs ( $10^{5}$ cells/Transwell $)$ were seeded into the upper compartment of invasion. The bottom chambers were filled with conditioned media from BC cells treated with thiostrepton or FoxM1 siRNA. After $24 \mathrm{~h}$ incubation, migrated cells were fixed, stained and quantified. (G-I) FoxM1 inhibition caused inhibition of HUVECs tube formation. HUVECs grown on matrigel were treated with conditioned media from thiostrepton or FoxM1 siRNA treated BC cells for $24 \mathrm{~h}$, cells were fixed, and tubular structures were photographed and quantified. Data presented in bar graphs are the mean $\pm \mathrm{SD}$ of three independent experiments. ${ }^{*}$ and \# indicate statistically significant differences compared to control/scramble siRNA without treatment or thiostrepton $(5 \mu \mathrm{M}) / \mathrm{siFoxM} 1(50 \mathrm{nM})$ treatment, respectively with $p<0.05$. 
of down-stream caspases and PARP. To confirm this, total cell lysate of CAL-120 and MDA-MB-231 cells following treatment with 5 and $10 \mu \mathrm{M}$ thiostrepton were immunoblotted with antibodies against caspases-9, -3 and PARP. There was a cleavage of caspases- $9,-3$ and PARP in both the cell lines treated with thiostrepton confirming caspase-dependent apoptosis in these cells (Figure 5E). To further confirm caspase dependent apoptosis in thiostrepton treated $\mathrm{BC}$ cells, we pre-treated $\mathrm{BC}$ cells with a universal inhibitor of caspase activation, zVAD-fmk, for three hours followed by treatment with $10 \mu \mathrm{M}$ thiostrepton for 48 hours. As compared to thiostrepton treated cells, there was inhibition of caspase activation and apoptosis in cells pretreated with zVAD-fmk confirming the role of caspases in thiostrepton-induced apoptosis in BC cells (Figure 5F).

\section{Down-regulation of FoxM1 regress in vivo $\mathrm{BC}$ xenografts}

Our in vitro data clearly indicated an important role of FoxM1 downregulation by thiostrepton in inhibiting
A

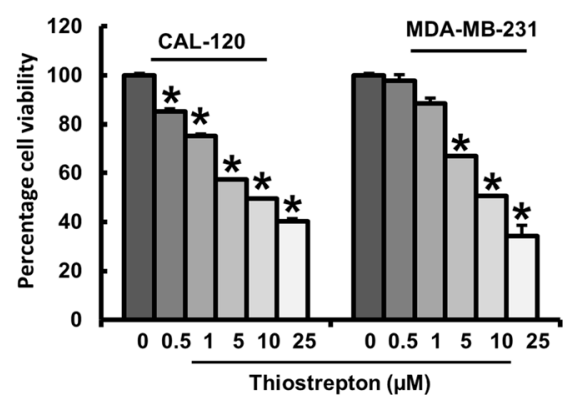

$\mathrm{D}$

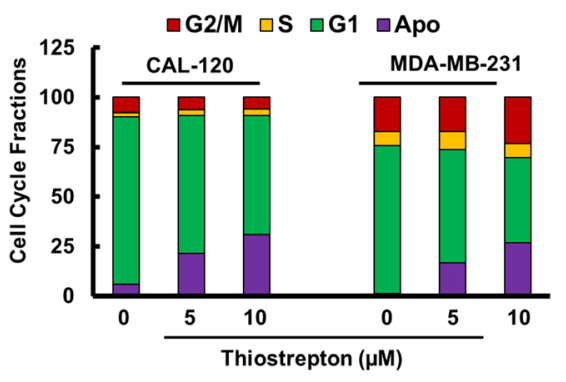

$\mathrm{F}$

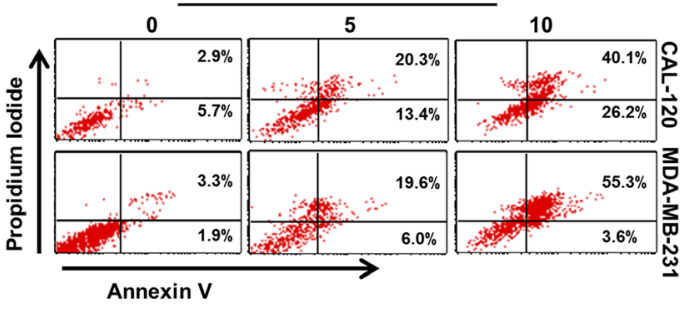

E
B

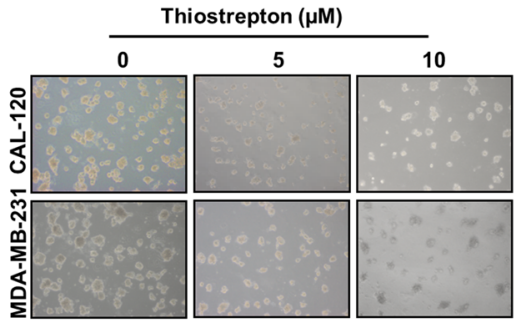

C

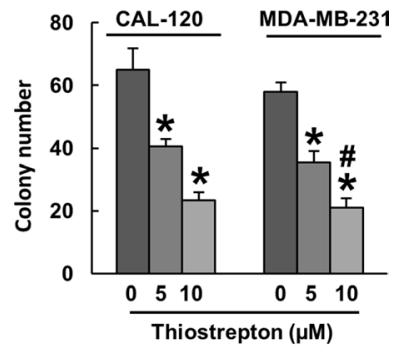

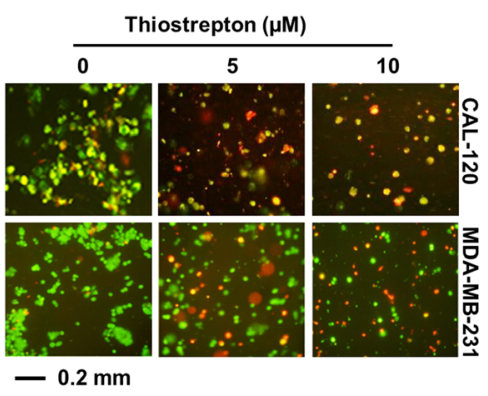

G

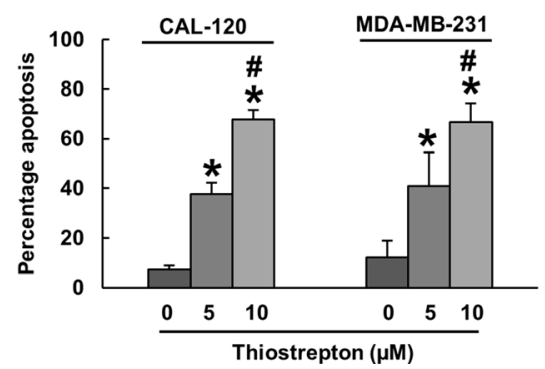

Figure 4: Thiostrepton treatment inhibited cell viability via induction of apoptosis in BC cells. (A) Thiostrepton induced inhibition of cell viability in BC cells. CAL-120 and MDA-MB-231 cells were incubated with different doses of thiostrepton ( $0.5-25 \mu \mathrm{M})$. Cell viability assays were performed using MTT as described in Materials and methods. The graph displays the mean $+/-$ SD (standard deviation) of three independent experiments with replicates of six wells for all the doses and vehicle control for each experiment ${ }^{*} p<0.01$, statistically significant (Students $t$-test). (B-C) Effect of thiostrepton on clonogenicity of BC cells. BC cells were treated with 5 and 10 $\mu \mathrm{M}$ thiostrepton and plated in soft agar for 4 weeks. After incubation, clonogenic assays were performed using as described in Materials and Methods. (D) Cell cycle analysis of BC cells treated with thiostrepton. CAL-120 and MDA-MB-231 cells were treated with 5 and $10 \mu \mathrm{M}$ thiostrepton for 48 hours. Following incubation, cells were analysed for cell cycle fractions by flow cytometry. (E) CAL-120 and MDA-MB-231 cells were treated with 5 and $10 \mathrm{mM}$ thiostrepton for 48 hours. Following treatment, cells were stained with Calcein AM and Ethidium homodimer as described in Material and Methods section and cells were analysed under a fluorescent microscope with a long-pass filter. $(\mathbf{F}-\mathbf{G})$ Thiostrepton-mediated apoptosis in BC cells. CAL-120 and MDA-MB-231 cells were treated with 5 and $10 \mu \mathrm{m}$ thiostrepton for 48 hours and cells were subsequently stained with fluorescein-conjugated annexin-V and propidium iodide and analysed by flow cytometry. Data presented in bar graphs are the mean \pm SD of three independent experiments. ${ }^{*}$ and ${ }^{\#}$ indicate statistically significant differences compared to control without treatment or thiostrepton $(5 \mu \mathrm{M})$ treatment, respectively with $p<0.05$. 
the invasion/migration capability and inducing apoptosis in $\mathrm{BC}$ cells. To further confirm these findings in vivo, we conducted experiments using nude female mice by generating xenografts of BC cell line, MDA-MB-231, and treating them with two different doses of thiostrepton
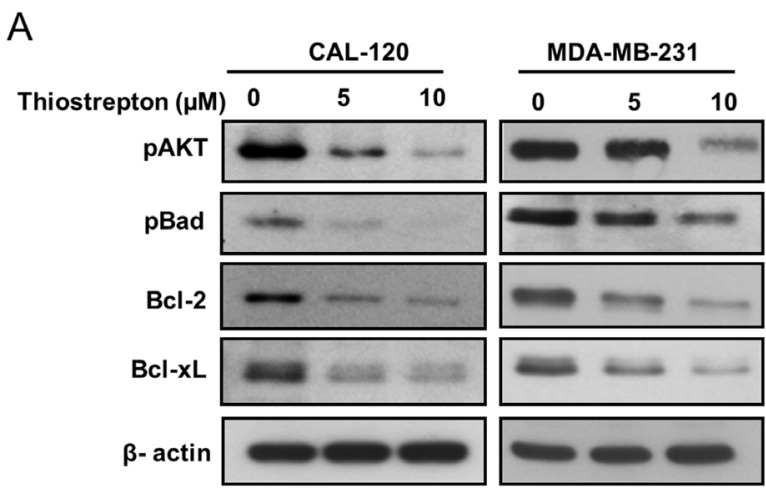

C

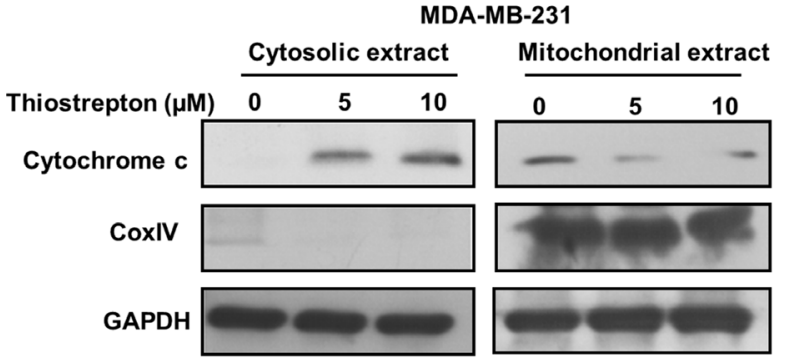

E

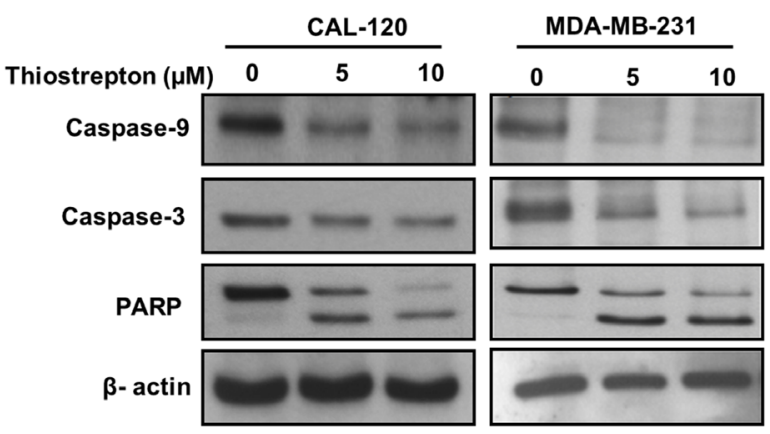

for a period of 4 weeks. After 4 weeks, the animals were sacrificed and their tumor weight was measured and proteins isolated. None of the animals experienced any weight loss, decreased activity or loss of appetite. We found that thiostrepton treatment decreased tumor

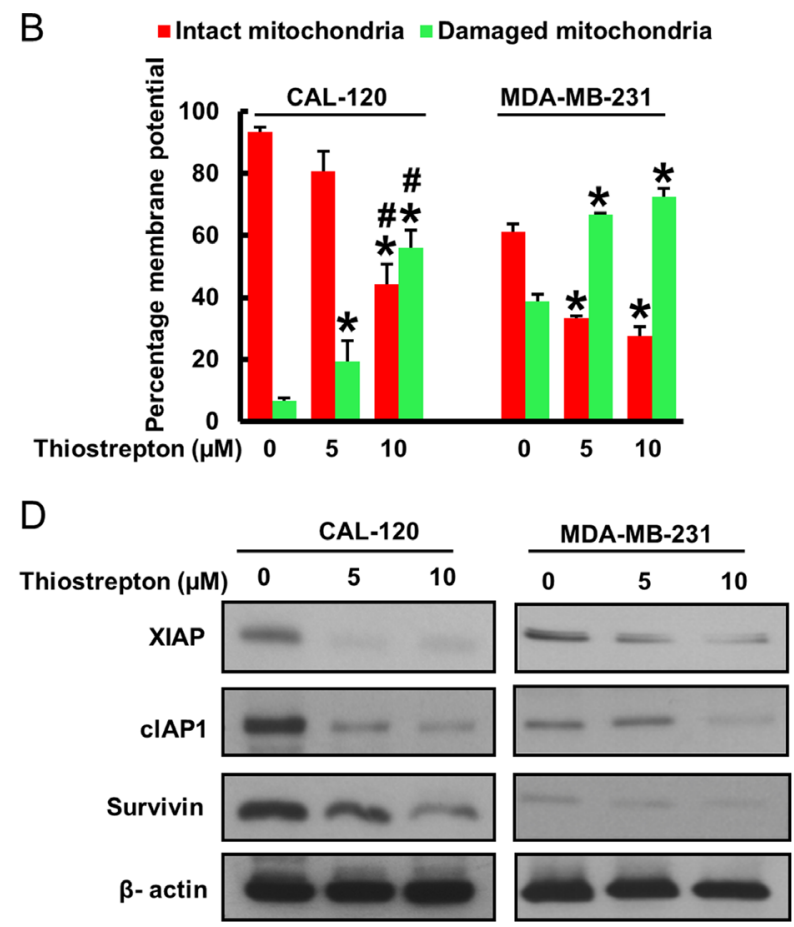

F

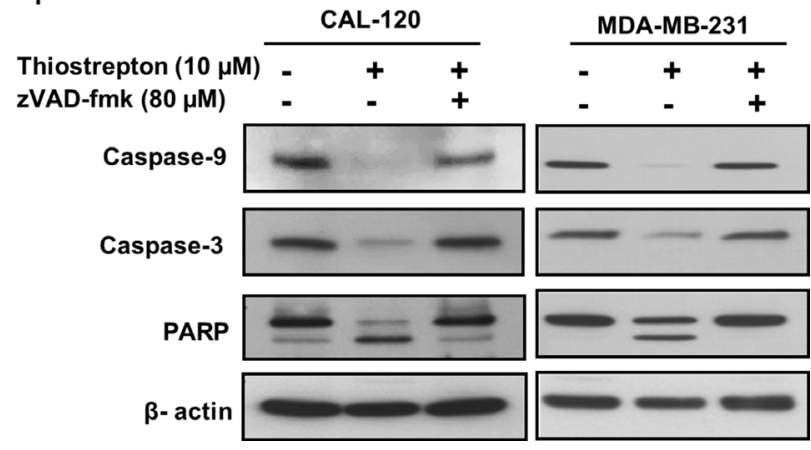

Figure 5: Thiostrepton treatment induces caspase-dependent apoptosis via activation of mitochondrial apoptotic pathway. (A) FoxM1 down-regulation leads to inactivation of AKT and down-stream target Bad in BC cells. CAL-120 and MDA-MB-231 cells were treated with 5 and $10 \mu \mathrm{M}$ thiostrepton for 48 hours. Following treatment, cells were lysed and immunoblotted with antibodies against p-AKT, p-Bad, Bcl-2, Bcl-xL and Beta-actin. (B) Estimation of mitochondrial membrane potential by flow cytometry. BC cells were treated with 5 and $10 \mu \mathrm{M}$ thiostrepton for 48 hours. Following treatment, cells were stained with $10 \mu \mathrm{M}$ JC1 and analysed by flow cytometry. (C) Thiostrepton-induced release of cytochrome c. MDA-MB-231 cells was treated with and without 5 and $10 \mathrm{mM}$ thiostrepton for 48 hours. Mitochondrial free, cytosolic fractions and mitochondrial extracts were isolated as described in Materials and Methods. Cell extracts were separated on SDS-PAGE, transferred to PVDF membrane, and immunoblotted with an antibody against cytochrome c, Cox IV and GAPDH. (D) BC cells were treated with thiostrepton (5 and $10 \mu \mathrm{M})$ for 48 hours and expression of XIAP, cIAP1 and Survivin were determined by immunoblotting. Beta-actin was used for equal loading. (E) Activation of caspases and cleavage of PARP induced by thiostrepton treatment in BC cells. BC cells were treated with and without 5 and $10 \mathrm{mM}$ thiostrepton for 48 hours. Cells were lysed, equal amount of proteins were separated on SDS-PAGE and immuno-blotted with antibodies against caspase-9, pro-caspase-3, PARP, and Betaactin. Each experiment was repeated three times to confirm reproducibility. (F) BC cells were pre-treated with either $80 \mathrm{mM} \mathrm{z-VAD/fmk}$ for 2 hours and treated with $10 \mathrm{mM}$ of thiostrepton for 48 hours and cells were lysed, equal amount of proteins were separated on SDS-PAGE and immuno-blotted with antibodies against pro-caspase-3, PARP and Beta-actin. Data presented in bar graphs are the mean \pm SD of three independent experiments. ${ }^{*}$ and ${ }^{\#}$ indicate statistically significant differences compared to control without treatment or thiostrepton $(5 \mu \mathrm{M})$ treatment, respectively with $p<0.05$. 
volume (Figure 6A) and weight (Figure 6B) at both doses used; however, doses of $80 \mathrm{mg} / \mathrm{kg}$ body weight caused a significant reduction of tumor volume and growth. Naked eye examination of post-necropsy tumors also clearly showed a reduction in size of tumor treated with thiostrepton as compared to vehicle treated tumors (Figure 6C). Finally, proteins isolated from tumors showed downregulation of FoxM1, VEGF, MMP-2, MMP-9, Bcl-xL, $\mathrm{XIAP}$ and $\beta$-actin following treatment with thiostrepton indicating that targeting FoxM1 can regress BC xenografts without any toxicity (Figure 6D).

\section{DISCUSSION}

Breast cancer (BC) continues to be the leading cause of morbidity in females in Saudi Arabia [38] and all over the world with an approximation of more than
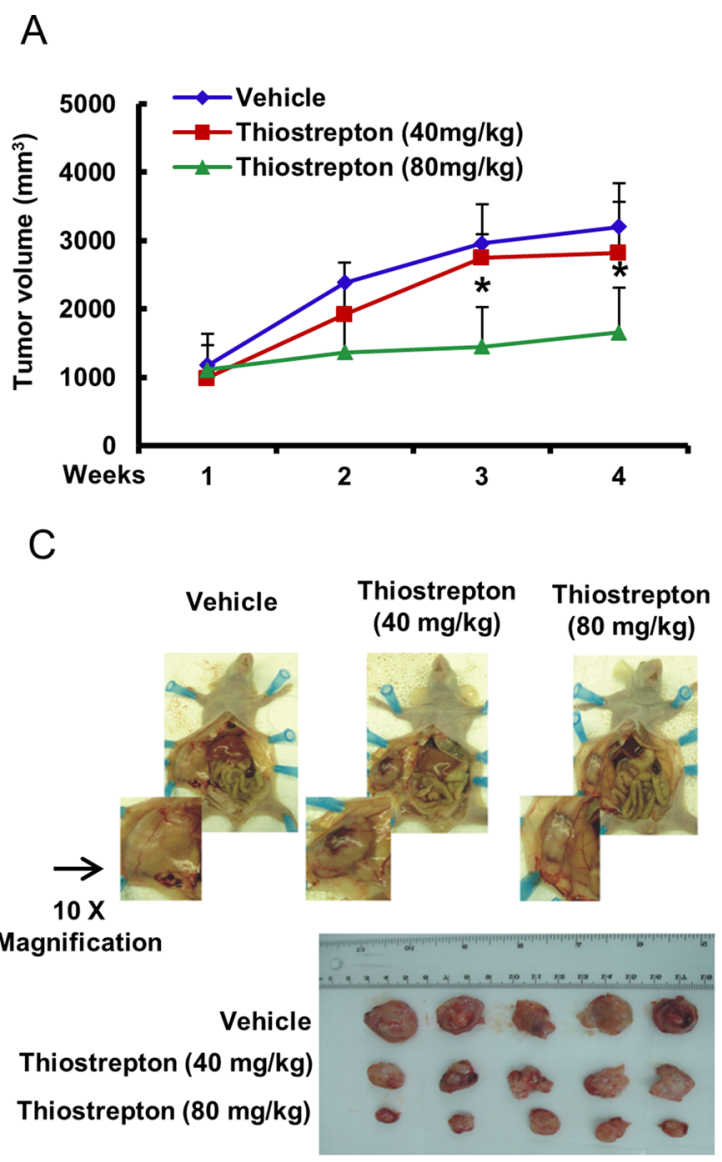

450,000 death per year [39]. Despite improvement in the treatment of breast cancer, the desired results have still not been achieved thereby prompting identification of new molecular targets that can be therapeutically utilized to improve the overall survival of breast cancer in this region. In order to identify these molecular targets, we analyzed a large cohort of breast cancer cases and found that FoxM1 was over-expressed in $79 \%$ of all BC studied. Previous studies have shown the expression and the prognostic significance of FoxM1 in several types of cancer including breast cancer [14, 15, 17-21]. However, the clinico-pathological significance of FoxM1 expression in Middle Eastern population has not been evaluated. Our results indicate that FoxM1 was over-expressed in a very high percentage of $\mathrm{BC}$ and was significantly associated with aggressive parameters like younger age, poorly differentiated tumors, mucinous histology and TNBC.
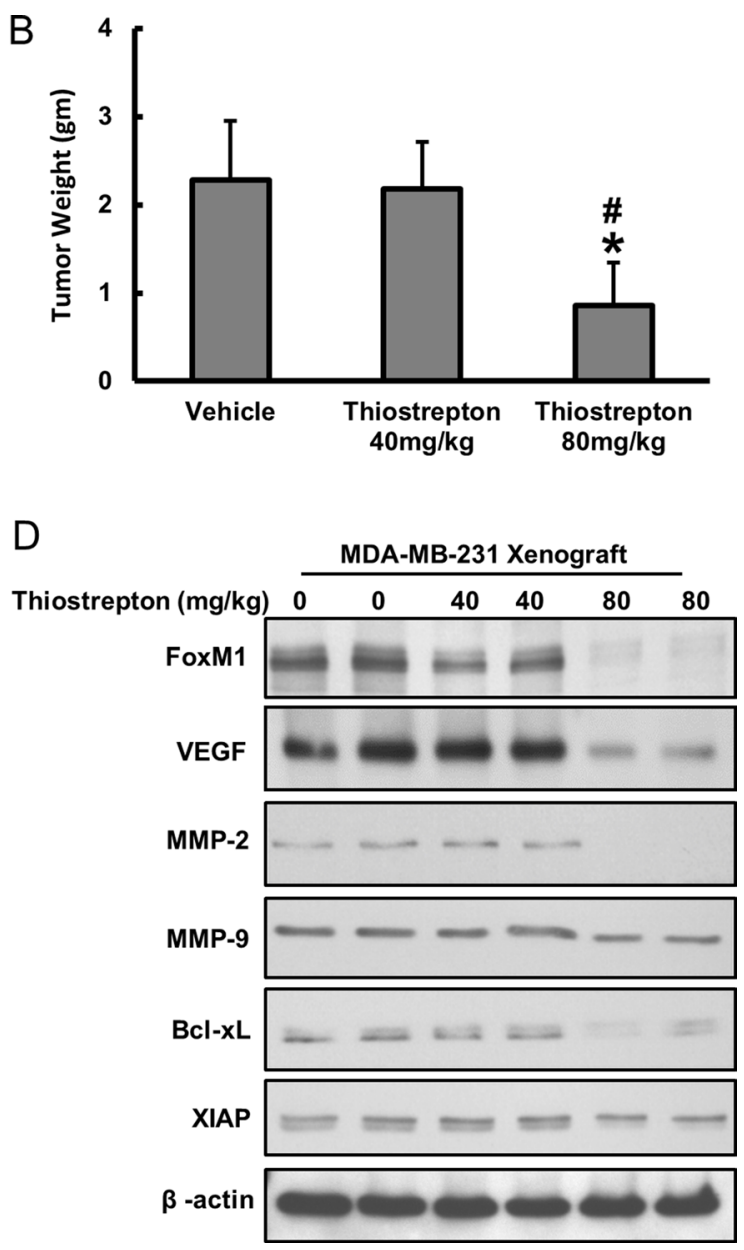

Figure 6: Thiostrepton-inhibits growth of MDA-MB-231 Xenografts. Female nude mice at 6 weeks of age were injected subcutaneuosly with $10 \times 10^{6}$ MDA-MB-231 cells. After one week, mice were treated with thiostrepton $40 \mathrm{mg} / \mathrm{kg} / \mathrm{dose}, 80 \mathrm{mg} / \mathrm{kg} / \mathrm{dose}$ and with 5\% DMSO in PBS as a vehicle control, (A) Volume of each tumor was measured every week. The average $(n=5)$ tumor volume of mice was calculated, ${ }^{*} p<0.05$ inhibition of BC tumor growth by thiostrepton. (B) After 4 weeks of treatment, mice were sacrificed and tumor weights were measured, ${ }^{*} p<0.05$ compared to vehicle-treated mice by Student's $t$-test. (C) Representative tumor images of vehicle and thiostrepton treated mice. (D) Whole cell lysate from mice treated with vehicle, thiostrepton (40 mg/ $\mathrm{kg}$ ) and thiostrepton $(80 \mathrm{mg} / \mathrm{kg})$ were isolated and $10 \mu \mathrm{g}$ protein were separated by SDS-PAGE, transferred to PVDF membrane, and immunoblotted with antibodies against FoxM1, VEGF, MMP-2, MMP-9, Bcl-xL, XIAP and Beta-actin. Data presented in bar graphs are the mean \pm SD of two independent experiments. ${ }^{*}$ and \#indicate statistically significant differences compared to vehicle or thiostrepton ( $40 \mathrm{mg} / \mathrm{kg}$ ) treatment, respectively with $p<0.05$. 
At the molecular level, we found that FoxM1 over-expression was significantly associated with Ki67, XIAP, p-AKT, MMP-9, Bcl-xL and VEGF. These data clearly indicate that FoxM1 over-expression in BC is an indicator of aggressive phenotype that warrants urgent intervention for management. Even though, FoxM1 overexpression was not found to be associated with overall poor survival, however, we found FoxM1 expression to be an independent marker for poor survival in late stage disease (Stage III and IV) in multivariate analysis. These findings also highlight the importance of identifying this subgroup of breast cancer with over-expression of FoxM1 early to adequately manage the disease before the disease progresses into a life threatening cancer.

In our study, we also detected a significant association between FoxM1 and aggressive parameters such as recurrence, poorly differentiated tumors, mucinous histology and TNBC in advanced stage BC (Stage III and IV). In addition, FoxM1 overexpression was also significantly associated with Ki67, XIAP, p-AKT, MMP9 and VEGF in advanced stage BC. Previous studies have shown the association of FoxM1 with VEGF, MMP9 and MMP-2 in various cancers leading to increased invasiveness and migratory ability of cancer cells causing metastasis, and targeting FoxM1 has been shown to inhibit this phenomena via down-regulation of VEGF, MMP-9 and MMP-2 [7, 26, 33, 40]. Our data is in concordance with these finding as we found a significant association between FoxM1 overexpression and VEGF and MMP-9 in our cohort of breast cancer cases.

Targeting FoxM1 using thiostrepton, a thiazole antibiotic has been shown to be beneficial in various cancers [41-43]. We also found that targeting FoxM1 expression with thiostrepton inhibited cell viability and induced mitochondrial dependent apoptosis in $\mathrm{BC}$ cells at doses that have previously been shown not to induce apoptosis in peripheral blood mononuclear cells [44]. Thiostrepton treatment caused damage to the mitochondrial membrane via conformational changes and upregulation of Bax with subsequent down-regulation of Bcl-2 and Bcl-xL, leading to release of cytochrome $\mathrm{c}$ and activation of caspases- 9 and -3 and eventually apoptosis. In addition to apoptosis, transcriptional down-regulation of FoxM1 also inhibited invasiveness, migratory and angiogenic capabilities of $\mathrm{BC}$ cells independent of apoptosis via down-regulation of VEGF, MMP-9 and MMP-2. Interestingly, VEGF transcriptional activation by FoxM1 is important for BC angiogenesis. These data clearly highlight the utility of thiostrepton, not only as an inducer of apoptosis but also as an agent that can decrease the ability of FoxM1 expressing cells to invade surrounding tissues eventually leading to metastasis.

Our in vivo data on BC xenografts treated with thiostrepton not only validated our in vitro findings by causing regression of tumor size and volume via downregulation of FoxM1 and its downstream targets; VEGF,
MMP-9, MMP-2, Bcl-xL and XIAP, but also gave an indication that thiostrepton can be used in humans as the doses of thiostrepton used did not induce toxicity, weight loss or lethargy in the experimental animals. These data clearly indicate the importance of targeting FoxM1 using thiostrepton for management of BC in the future.

In summary, our results show that FoxM1 expression was found to be increased in Middle Eastern BC. We also presented experimental evidence that strongly support the role of FoxM1 in tumor progression and metastasis of $\mathrm{BC}$. The current study demonstrates that down regulation of FoxM1 could potentially be an effective approach for inhibiting VEGF, MMP-2 and MMP-9 which is likely to result in inhibition of cell growth, invasion, angiogenesis and metastasis of BC. Targeting FoxM1 over-expressing $\mathrm{BC}$ with thiostrepton either accompanied with chemotherapy or as maintenance after chemotherapy maybe beneficial in these aggressive cancers that currently have no identified therapeutic targets that can be targeted for management. Finally, further studies are required to validate the efficacy of targeting FoxM1 expression with combination of other currently used chemotherapeutic agents for response and toxicity in $\mathrm{BC}$.

\section{MATERIALS AND METHODS}

\section{Patient selection and tissue microarray construction}

One thousand and nine (1009) clinical samples from patients diagnosed with BC between 1990-2012 at King Faisal Specialist Hospital and Research Center (KFSHRC) were collected with complete clinical and histopathological data. All the collected formalin-fixed, paraffin-embedded blocks were processed for preparation of a TMA as described previously [45]. After TMA preparation, slides were prepared and manual staining was performed as described before [46]. Institutional Review Board (IRB) of the King Faisal Specialist Hospital \& Research Centre approved the study (RAC \# 2140008 and 2110025 ).

\section{Immunohistochemistry (IHC) Staining}

Standard protocol was followed for IHC staining. For antigen retrieval, Dako (Dako Denmark A/S, Glostrup, Denmark) Target Retrieval Solution pH 9.0 (Catalog number S2368) was used, and the slides were microwaved at $750 \mathrm{~W}$ for $5 \mathrm{~min}$ and then at $250 \mathrm{~W}$ for $20 \mathrm{~min}$. The primary antibodies used for staining tissue microarray sections and their dilutions are listed in Supplementary Table 1. The Dako Envision Plus System kit was used as the secondary detection system with 3, 30-diaminobenzidine as chromogen. All slides were counterstained with haematoxylin, dehydrated, cleared and mounted. Negative controls included omission of the primary antibody. Normal 
tissues of different organ system were also included in the TMA to serve as control. Only fresh cut slides were stained simultaneously to minimize the influence of slide aging and maximize reproducibility of the experiment.

\section{IHC scoring}

Each TMA spot was assigned an intensity score from 0 to 3 (I0, I1-I3) and the proportion of tumor staining for that intensity was recorded as $5 \%$ increments from a range of 0-100 (P0, P1-P3). A final H score (range 0-300) was obtained by adding the sum of scores obtained for each intensity and proportion of area stained $(\mathrm{H}$ score $=\mathrm{I} 1 \times \mathrm{P} 1+$ $\mathrm{I} 2 \times \mathrm{P} 2+\mathrm{I} 3 \times \mathrm{P} 3$ ). FoxM1 was standardized, validated and scored as described earlier [40]. Using X-tile version 3.6.1 [40], we defined the optimal cut-off point for FoxM1, XIAP, Bcl-xL, VEGF and MMP-9. Based on X-tile plots, Breast cancer patients were sub-grouped into two groups, one with complete absence of staining $(\mathrm{H}$ score $=0)$ was defined as no expression; the other group with staining $(\mathrm{H}$ score $>0$ ) was defined as over-expression for FoxM1. Similarly, X-tile was used to classify breast cancer patients into subgroups based on expression of Bcl-xL, XIAP, VEGF and MMP-9 as described previously [40].

\section{Cell culture}

BC cell lines, CAL-120 and MDA-MB-231 were purchased from American Type Culture Collection (ATCC) and grown in RPMI1640 media supplemented with 10\% FBS. Human umbilical vein endothelial cells (HUVECs) were purchased from ATCC and grown in EBM-2 (Lonza, Walkersville, MD). Cells were cultured at $37^{\circ} \mathrm{C}$ under a humidified 95\%: 5\% (v/v) mixture of air and $\mathrm{CO}_{2}$.

\section{Reagents and antibodies}

Thiostrepton (FoxM1 selective inhibitor) was purchased from Tocris Cookson Inc (Ellisville, MO). Antibodies against caspase-3, caspase-9, p-AKT, Cox IV, $\beta$-actin, MMP-2, MMP-9, Bcl-2, BID, Bcl-xL and poly (ADP) ribose polymerase (PARP) antibodies were purchased from Cell Signaling Technologies (Beverly, MA). FoxM1, VEGF, Cytochrome c and GAPDH antibodies were purchased from Santa Cruz Biotechnology, Inc. (Santa Cruz, CA). XIAP antibody and trans-well invasion and migration kits were purchased from BD Biosciences (San Jose, CA). Annexin V and JC1 were purchased from Thermo Fisher Scientific (Waltham, MA). Live dead assay kit was purchased from Life Technologies (Grand Island, NY).

\section{Cell viability MTT assay}

BC cells were plated at a concentration of $10^{4}$ cells in $0.2 \mathrm{ml}$ of media in a 96 well format for 24 hours.
Following incubation, cells were treated with various concentrations of thiostrepton for 48 hours and cells were stained with MTT and analyzed on a colorimetric plate reader as described previously [40].

\section{Cell death and apoptosis analysis}

BC cells were treated with different concentrations of thiostrepton for 48 hours and analyzed for cell death and apoptosis. For cell death, following treatment, cells were stained with Calcein and Ethidium homodimers as described before [47]. The cells were then examined under a microscope with long pass filter. For cell cycle analysis and apoptosis, cells were either stained with Propidium iodide alone for cell cycle or annexin V and Propidium iodide for apoptosis and analyzed by flow cytometry as previously described [48].

\section{Cell lysis and immunoblotting}

Following treatment, BC cells were lysed in phosphorylation lysis buffer containing $50 \mathrm{mM}$ Hepes $(\mathrm{pH}$ 7.3), $150 \mathrm{mM} \mathrm{NaCl}, 1.5 \mathrm{mM} \mathrm{MgCl}, 1.0 \mathrm{mM}$ EDTA (pH 8.0), $100 \mathrm{mM} \mathrm{NaF}, 10 \mathrm{mM} \mathrm{Na}_{2} \mathrm{H}_{2} \mathrm{P}_{2} \mathrm{O}_{7}, 200 \mu \mathrm{M} \mathrm{Na}_{3} \mathrm{VO}_{4}$ and $1 \mathrm{X}$ proteasome inhibitors (Roche pharmaceuticals, Basel, Switzerland). Following lysis, cells were spun at 14,000 rpm for 15 minutes at $4{ }^{\circ} \mathrm{C}$ and protein amounts were measured using Bradford assay (Life Technologies). Equal amounts of protein were separated on SDS-Page and immunoblotted with different antibodies as described previously [49].

\section{Gene silencing using siRNA}

Non-specific control siRNA and FoxM1 specific siRNA were used to transfect BC cells using Lipofectamine 2000 (Invitrogen, Carlsbad, CA) as described by the manufacturer. Following transfection, cells were harvested and proteins were isolated and immunoblotted with different antibodies.

\section{Measurement of mitochondrial membrane potential and cytochrome c release}

Following treatment with thiostrepton for 48 hours, $\mathrm{BC}$ cells were harvested and stained with $\mathrm{JC} 1$ dye for 30 minutes at $37^{\circ} \mathrm{C}$ and analyzed by flow cytometry. In the same experiment, cells were also fractionized into mitochondrial free cytosolic and cytosolic free mitochondrial fractions and separated on SDS-Page for immunoblotting as described previously [40, 50].

\section{Soft agar colony assays}

BC cells were treated with thiostrepton for 48 hours and then plated in $0.5 \mathrm{ml}$ culture medium containing $0.4 \%(\mathrm{v} / \mathrm{v})$ top agar and $20 \%$ FBS layered 
over a basal layer of $0.8 \%(\mathrm{v} / \mathrm{v})$ agar and $20 \% \mathrm{FBS}$. The cells were then incubated at $37^{\circ} \mathrm{C}$ in $5 \% \mathrm{CO}_{2}$ for 4 weeks as described previously [14]. After 4 weeks incubation, cells were stained with staining solution (EMD Millipore, Billerica, MA) and visualized under an inverted microscope.

\section{Cell invasion and migration assays}

Cell invasion and migration assay were performed as described previously [26]. Briefly, after treatment of cells with thiostrepton for 48 hours, cells were re-counted and equal number of cells were seeded into Trans-well inserts either uncoated (for migration assay) or coated (for invasion assay) with growth factor-reduced matrigel for 24 hours. After incubation, cells were stained with Diff-Quick stain set (Fisher Scientific, Pittsburg, PA), and photographed under a fluorescent microscope.

\section{Wound-healing migration assay}

HUVECs were grown into wells of collagen coated 24 well plate dishes to $100 \%$ confluence. Cells were starved to inactivate cell proliferation and then wounded by $200 \mu \mathrm{l}$ pipette tips. EBM- 2 containing $0.5 \%$ FBS was added along with conditioned medium collected from BC cells with or without thiostrepton treatments. Images of the cells were taken after $24 \mathrm{~h}$ of incubation. The wound area was measured using Image $J$ software, and data was expressed as percentage of open wound area calculated by dividing migrated distance by scratched distance. Three independent experiments were performed.

\section{Capillary-like tube formation assay}

HUVECs in EBM-2 medium were seeded into the matrigel layer in 24-well plates at a density of $6 \times 10^{4}$ cells/well. Conditioned media from thiostrepton treated and untreated BCs cells were added into the wells and incubated for $24 \mathrm{~h}$ at $37^{\circ} \mathrm{C}$ in $5 \% \mathrm{CO}_{2}$ atmosphere. Tube formation was examined and photographed using an inverted microscope (20X) [35].

\section{Immunofluorescence analysis}

$\mathrm{BC}$ cells grown on coverslips in 6-well plates were fixed with ice-cold $100 \%$ methanol followed by permeabilization with $0.2 \%$ Triton X-100, blocked with $5 \%$ horse serum in PBS solution, and incubated with antibodies to FoxM1 (sc-376471, 1:100) and VEGF (ab46154, 1:200) in buffer A (1\% BSA, 0.1\% Triton $\mathrm{X}-100,10 \%$ horse serum in PBS solution) for $1 \mathrm{~h}$ at $37^{\circ} \mathrm{C}$. Cells were then incubated with Alexa Fluor 488 goat antimouse or Alexa Fluor 594 goat anti-rabbit antibody and mounted using DAPI. The cells were visualized using Olympus BX63 fluorescence microscope.

\section{Chromatin immunoprecipitation (ChIP) assay}

ChIP analysis was performed using a Pierce TMA garose ChIP Kit (Thermo Scientific, Rockford, IL). Sheared chromatin was diluted and immunoprecipitated with $2 \mu \mathrm{g}$ of anti-FoxM1 or control IgG antibody. DNA protein complexes were eluted from protein $A / G$ agarose beads using a spin column and were reverse cross-linked by incubating with $\mathrm{NaCl}$ at $65^{\circ} \mathrm{C}$. The intensity of FoxM1 binding to the VEGF promoter was analyzed by Applied Biosystems ${ }^{\circledR} 7500$ Fast RealTime PCR Detection System with SYBR Green PCR master mix using following primer sequences, FoxM1 binding to the VEGF promoter sites, F1 ( $-1,635$ to $-1,420 \mathrm{bp}$ ): (F) GGAGCGTTTTGGTTAAATTGAG and (R) TGCATATAGGAAGCAGCTTGGA; F2 (-634 to $-442 \mathrm{bp}$ ): (F) CCCCTTTCCAAAGCCCATTCC and (R) CCTTCTCCCCGCTCCAACACCC. General PCR

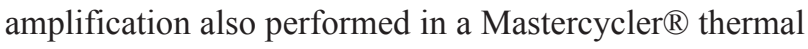
cycler (Eppendorf, Foster City, CA).

\section{Animals and xenografts study}

Six-weeks old female nude mice were obtained from Jackson Laboratories (Bar Harbor, ME) and maintained in a pathogen-free animal facility at least 1 week before use. All animal studies were done in accordance with institutional guidelines. For xenograft study, MDA-MB-231 cells $\left(10 \times 10^{6}\right.$ cells per mouse $)$ were resuspended in serum-free media $(200 \mu \mathrm{l})$ and subcutaneously injected into the right abdominal quadrant of nude mice. After 1 week, mice were randomly segregated into three groups. Mice were then treated with two doses of thiostrepton $40 \mathrm{mg} / \mathrm{kg} / \mathrm{dose}$ and 80 $\mathrm{mg} / \mathrm{kg} /$ dose dissolved in DMSO intra peritoneal (i.p) twice weekly and vehicle DMSO-treated control groups, $(n=5)$. After 4 weeks of treatment, mice were sacrificed and tumors were collected. The body weight and tumor volume of each mouse was monitored weekly [40].

\section{Statistical analysis}

Contingency table analysis and chi-square tests were used to study the relationship between clinicopathological variables and FoxM1 expression. Survival curves were generated using the Kaplan-Meier method, with significance evaluated using the Mantel-Cox log-rank test. The limit of significance for all analyses was defined as a $p$-value $<0.05$. The JMP 11.0 (SAS Institute, Inc., Cary, NC) software package was used for data analyses.

For all functional studies, data presented are means $\pm \mathrm{SD}$ of triplicates in an independent experiment, which was repeated for at least two times with the same results. For multiple comparisons, one-way analysis of variance (ANOVA) was performed using IBM SPSS Statistics 21 software (IBM Corp., Armonk, NY). Values of $p<0.05$ were considered statistically significant. 


\section{Author contributions}

AKS and PP: Designed, performed experiments and wrote the manuscript, ST, SOA and ZQ: Performed experiments and statistical analysis, FA, AT and DA: Collected and analyzed all the clinical samples and data, SKP: Prepared the TMA and conducted all the immunohistochemistry experiments and scoring of IHC spots, KSA: Made substantial contributions to conception, design and acquisition of data along with analysis and interpretation of data; Prepared and wrote the manuscript. KSA gave the final approval for the submission of the manuscript. This is to confirm that all authors read and approved the final manuscript.

\section{ACKNOWLEDGMENTS AND FUNDING}

We would like to acknowledge Dr. Maqbool Ahmed, Dr. Divya Sasidharan Padmaja, Rafia Begum, Roxanne Melosantos, Valorie M. Balde and Padmanaban Annaiyappanaidu for their technical assistance. This study was not supported by any funding agency therefore the authors declare that there is no funding information to be disclosed for this manuscript.

\section{CONFLICTS OF INTEREST}

There are no conflicts of interest to report.

\section{REFERENCES}

1. American Cancer Society. Cancer Facts \& Figures 2013. Atlanta: American Cancer Society. 2013.

2. Munster PN, Moore AP, Ismail-Khan R, Cox CE, Lacevic M, Gross-King M, Xu P, Carter WB, Minton SE. Randomized trial using gonadotropin-releasing hormone agonist triptorelin for the preservation of ovarian function during (neo)adjuvant chemotherapy for breast cancer. J Clin Oncol. 2012; 30:53338. https://doi.org/10.1200/JCO.2011.34.6890.

3. Lin LZ, Cai MG, Dai YC, Zheng ZB, Jiang FF, Shi LL, Pan $\mathrm{Y}$, Song HB. BRMS1 gene expression may be associated with clinico-pathological features of breast cancer. Biosci Rep. 2017; 37:BSR20170672. https://doi.org/10.1042/ BSR20170672.

4. Al Tamimi DM, Shawarby MA, Ahmed A, Hassan AK, AlOdaini AA. Protein expression profile and prevalence pattern of the molecular classes of breast cancer - a Saudi population based study. BMC Cancer. 2010; 10:223. https:// doi.org/10.1186/1471-2407-10-223.

5. Al-Kuraya K, Schraml P, Sheikh S, Amr S, Torhorst J, Tapia C, Novotny H, Spichtin H, Maurer R, Mirlacher M, Simon R, Sauter G. Predominance of high-grade pathway in breast cancer development of Middle East women. Mod Pathol. 2005; 18:891-97. https://doi.org/10.1038/ modpathol.3800408.
6. Griffiths CL, Olin JL. Triple negative breast cancer: a brief review of its characteristics and treatment options. J Pharm Pract. 2012; 25:319-23. https://doi. org/10.1177/0897190012442062.

7. Xue YJ, Xiao RH, Long DZ, Zou XF, Wang XN, Zhang GX, Yuan YH, Wu GQ, Yang J, Wu YT, Xu H, Liu FL, Liu M. Overexpression of FoxM1 is associated with tumor progression in patients with clear cell renal cell carcinoma. J Transl Med. 2012; 10:200. https://doi.org/10.1186/1479_ 5876-10-200.

8. Leung TW, Lin SS, Tsang AC, Tong CS, Ching JC, Leung WY, Gimlich R, Wong GG, Yao KM. Over-expression of FoxM1 stimulates cyclin B1 expression. FEBS Lett. 2001; 507:59-66. https://doi.org/10.1016/S0014-5793(01)02915-5.

9. Wang IC, Chen YJ, Hughes D, Petrovic V, Major ML, Park HJ, Tan Y, Ackerson T, Costa RH. Forkhead box M1 regulates the transcriptional network of genes essential for mitotic progression and genes encoding the SCF (Skp2Cks1) ubiquitin ligase. Mol Cell Biol. 2005; 25:10875-94. https://doi.org/10.1128/MCB.25.24.10875-10894.2005.

10. Raychaudhuri P, Park HJ. FoxM1: a master regulator of tumor metastasis. Cancer Res. 2011; 71:4329-33. https:// doi.org/10.1158/0008-5472.CAN-11-0640.

11. Halasi M, Gartel AL. FOX(M1) news-it is cancer. Mol Cancer Ther. 2013; 12:245-54. https://doi. org/10.1158/1535-7163.MCT-12-0712.

12. Hu C, Liu D, Zhang Y, Lou G, Huang G, Chen B, Shen X, Gao M, Gong W, Zhou P, Dai S, Zeng Y, He F. LXR $\alpha$ mediated downregulation of FoxM1 suppresses the proliferation of hepatocellular carcinoma cells. Oncogene. 2014; 33:2888-97. https://doi.org/10.1038/onc.2013.250.

13. Wang X, Krupczak-Hollis K, Tan Y, Dennewitz MB, Adami GR, Costa RH. Increased hepatic Forkhead Box M1B (FoxM1B) levels in old-aged mice stimulated liver regeneration through diminished $\mathrm{p} 27 \mathrm{Kip} 1$ protein levels and increased Cdc25B expression. J Biol Chem. 2002; 277:44310-16. https://doi.org/10.1074/jbc.M207510200.

14. Wang M, Gartel AL. The suppression of FoxM1 and its targets in breast cancer xenograft tumors by siRNA. Oncotarget. 2011; 2:1218-26. https://doi.org/10.18632/ oncotarget.359.

15. Miao L, Xiong X, Lin Y, Cheng Y, Lu J, Zhang J, Cheng N. Down-regulation of FoxM1 leads to the inhibition of the epithelial-mesenchymal transition in gastric cancer cells. Cancer Genet. 2014; 207:75-82. https://doi.org/10.1016/j. cancergen.2014.02.008.

16. Park HJ, Gusarova G, Wang Z, Carr JR, Li J, Kim KH, Qiu J, Park YD, Williamson PR, Hay N, Tyner AL, Lau LF, Costa RH, Raychaudhuri P. Deregulation of FoxM1b leads to tumour metastasis. EMBO Mol Med. 2011; 3:21-34. https://doi.org/10.1002/emmm.201000107.

17. Kambach DM, Sodi VL, Lelkes PI, Azizkhan-Clifford J,

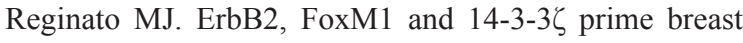
cancer cells for invasion in response to ionizing radiation. 
Oncogene. 2014; 33:589-98. https://doi.org/10.1038/ onc.2012.629.

18. Liu D, Zhang Z, Kong CZ. High FoxM1 expression was associated with bladder carcinogenesis. Tumour Biol. 2013; 34:1131-38. https://doi.org/10.1007/s13277-013-0654-x.

19. Christensen L, Joo J, Lee S, Wai D, Triche TJ, May WA. FoxM1 is an oncogenic mediator in Ewing Sarcoma. PLoS One. 2013; 8:e54556. https://doi.org/10.1371/journal. pone.0054556.

20. Wu QF, Liu C, Tai MH, Liu D, Lei L, Wang RT, Tian M, Lü Y. Knockdown of FoxM1 by siRNA interference decreases cell proliferation, induces cell cycle arrest and inhibits cell invasion in MHCC-97H cells in vitro. Acta Pharmacol Sin. 2010; 31:361-66. https://doi.org/10.1038/aps.2010.4.

21. He SY, Shen HW, Xu L, Zhao XH, Yuan L, Niu G, You ZS, Yao SZ. FoxM1 promotes tumor cell invasion and correlates with poor prognosis in early-stage cervical cancer. Gynecol Oncol. 2012; 127:601-10. https://doi.org/10.1016/j. ygyno.2012.08.036.

22. Francis RE, Myatt SS, Krol J, Hartman J, Peck B, McGovern UB, Wang J, Guest SK, Filipovic A, Gojis O, Palmieri C, Peston D, Shousha S, et al. FoxM1 is a downstream target and marker of HER2 overexpression in breast cancer. Int J Oncol. 2009; 35:57-68.

23. Park YY, Jung SY, Jennings NB, Rodriguez-Aguayo C, Peng G, Lee SR, Kim SB, Kim K, Leem SH, Lin SY, Lopez-Berestein G, Sood AK, Lee JS. FoxM1 mediates Dox resistance in breast cancer by enhancing DNA repair. Carcinogenesis. 2012; 33:1843-53. https://doi.org/10.1093/ carcin/bgs 167.

24. Kwok JM, Peck B, Monteiro LJ, Schwenen HD, Millour J, Coombes RC, Myatt SS, Lam EW. FoxM1 confers acquired cisplatin resistance in breast cancer cells. Mol Cancer Res. 2010; 8:24-34. https://doi.org/10.1158/1541-7786.MCR09-0432.

25. Carr JR, Park HJ, Wang Z, Kiefer MM, Raychaudhuri P. FoxM1 mediates resistance to herceptin and paclitaxel. Cancer Res. 2010; 70:5054-63. https://doi. org/10.1158/0008-5472.CAN-10-0545.

26. Ahmed M, Hussain AR, Siraj AK, Uddin S, Al-Sanea N, AlDayel F, Al-Assiri M, Beg S, Al-Kuraya KS. Co-targeting of Cyclooxygenase-2 and FoxM1 is a viable strategy in inducing anticancer effects in colorectal cancer cells. Mol Cancer. 2015; 14:131. https://doi.org/10.1186/s12943-0150406-1.

27. Yang K, Jiang L, Hu Y, Yu J, Chen H, Yao Y, Zhu X. Short hairpin RNA- mediated gene knockdown of FoxM1 inhibits the proliferation and metastasis of human colon cancer cells through reversal of epithelial-to-mesenchymal transformation. J Exp Clin Cancer Res. 2015; 34:40. https:// doi.org/10.1186/s13046-015-0158-1.

28. Uddin S, Ahmed M, Hussain A, Abubaker J, Al-Sanea N, AbdulJabbar A, Ashari LH, Alhomoud S, Al-Dayel F, Jehan Z, Bavi P, Siraj AK, Al-Kuraya KS. Genome-wide expression analysis of Middle Eastern colorectal cancer reveals FoxM1 as a novel target for cancer therapy. Am J Pathol. 2011; 178:537-47. https://doi.org/10.1016/j. ajpath.2010.10.020.

29. Jiang L, Wang P, Chen H. Overexpression of FoxM1 is associated with metastases of nasopharyngeal carcinoma. Ups J Med Sci. 2014; 119:324-32. https://doi.org/10.3109/ 03009734.2014.960053.

30. Wen N, Wang Y, Wen L, Zhao SH, Ai ZH, Wang Y, Wu B, Lu HX, Yang H, Liu WC, Li Y. Overexpression of FoxM1 predicts poor prognosis and promotes cancer cell proliferation, migration and invasion in epithelial ovarian cancer. J Transl Med. 2014; 12:134. https://doi. org/10.1186/1479-5876-12-134.

31. Wierstra I. FoxM1 (Forkhead box M1) in tumorigenesis: overexpression in human cancer, implication in tumorigenesis, oncogenic functions, tumor-suppressive properties, and target of anticancer therapy. Adv Cancer Res. 2013; 119:191-419. https://doi.org/10.1016/B978-012-407190-2.00016-2.

32. Jacob A, Prekeris R. The regulation of MMP targeting to invadopodia during cancer metastasis. Front Cell Dev Biol. 2015; 3:4. https://doi.org/10.3389/fcell.2015.00004.

33. Zhang Y, Zhang N, Dai B, Liu M, Sawaya R, Xie K, Huang $\mathrm{S}$. FoxM1B transcriptionally regulates vascular endothelial growth factor expression and promotes the angiogenesis and growth of glioma cells. Cancer Res. 2008; 68:8733-42. https://doi.org/10.1158/0008-5472.CAN-08-1968.

34. Bhat UG, Halasi M, Gartel AL. FoxM1 is a general target for proteasome inhibitors. PLoS One. 2009; 4:e6593. https://doi.org/10.1371/journal.pone.0006593.

35. Pratheeshkumar P, Budhraja A, Son YO, Wang X, Zhang Z, Ding S, Wang L, Hitron A, Lee JC, Xu M, Chen G, Luo J, Shi X. Quercetin inhibits angiogenesis mediated human prostate tumor growth by targeting VEGFR- 2 regulated AKT/mTOR/P70S6K signaling pathways. PLoS One. 2012; 7:e47516. https://doi.org/10.1371/journal.pone.0047516.

36. Hussain AR, Al-Rasheed M, Manogaran PS, Al-Hussein KA, Platanias LC, Al Kuraya K, Uddin S. Curcumin induces apoptosis via inhibition of PI3'-kinase/AKT pathway in acute T cell leukemias. Apoptosis. 2006; 11:245-54. https:// doi.org/10.1007/s10495-006-3392-3.

37. Yao A, Shen Y, Wang A, Chen S, Zhang H, Chen F, Chen Z, Wei H, Zou Z, Shan Y, Zhang X. Sulforaphane induces apoptosis in adipocytes via Akt/p70s6k1/Bad inhibition and ERK activation. Biochem Biophys Res Commun. 2015; 465:696-701. https://doi.org/10.1016/j.bbrc.2015.08.049.

38. Roshandel G, Boreiri M, Sadjadi A, Malekzadeh R. A diversity of cancer incidence and mortality in West Asian populations. Ann Glob Health. 2014; 80:346-57. https://doi. org/10.1016/j.aogh.2014.09.012.

39. Siegel R, Naishadham D, Jemal A. Cancer statistics, 2013. CA Cancer J Clin. 2013; 63:11-30. https://doi.org/10.3322/ caac. 21166. 
40. Ahmed M, Uddin S, Hussain AR, Alyan A, Jehan Z, Al-Dayel F, Al-Nuaim A, Al-Sobhi S, Amin T, Bavi P, Al-Kuraya KS. FoxM1 and its association with matrix metalloproteinases (MMP) signaling pathway in papillary thyroid carcinoma. J Clin Endocrinol Metab. 2012; 97:E113. https://doi.org/10.1210/jc.2011-1506.

41. Ju SY, Huang CY, Huang WC, Su Y. Identification of thiostrepton as a novel therapeutic agent that targets human colon cancer stem cells. Cell Death Dis. 2015; 6:e1801. https://doi.org/10.1038/cddis.2015.155.

42. Buchner M, Park E, Geng H, Klemm L, Flach J, Passegué E, Schjerven H, Melnick A, Paietta E, Kopanja D, Raychaudhuri P, Müschen M. Identification of FoxM1 as a therapeutic target in B-cell lineage acute lymphoblastic leukaemia. Nat Commun. 2015; 6:6471. https://doi. org/10.1038/ncomms7471.

43. Yu C, Chen L, Yie L, Wei L, Wen T, Liu Y, Chen H. Targeting FoxM1 inhibits proliferation, invasion and migration of nasopharyngeal carcinoma through the epithelial-to-mesenchymal transition pathway. Oncol Rep. 2015; 33:2402-10. https://doi.org/10.3892/or.2015.3834.

44. Uddin S, Hussain AR, Ahmed M, Siddiqui K, Al-Dayel F, Bavi P, Al-Kuraya KS. Overexpression of FoxM1 offers a promising therapeutic target in diffuse large B-cell lymphoma. Haematologica. 2012; 97:1092-100. https://doi. org/10.3324/haematol.2011.053421.

45. Beg S, Siraj AK, Prabhakaran S, Jehan Z, Ajarim D, Al-Dayel F, Tulbah A, Al-Kuraya KS. Loss of PTEN expression is associated with aggressive behavior and poor prognosis in Middle Eastern triple-negative breast cancer. Breast Cancer Res Treat. 2015; 151:541-53. https://doi. org/10.1007/s10549-015-3430-3.
46. Uddin S, Hussain AR, Siraj AK, Manogaran PS, AlJomah NA, Moorji A, Atizado V, Al-Dayel F, Belgaumi A, El-Solh H, Ezzat A, Bavi P, Al-Kuraya KS. Role of phosphatidylinositol 3'-kinase/AKT pathway in diffuse large B-cell lymphoma survival. Blood. 2006; 108:417886. https://doi.org/10.1182/blood-2006-04-016907.

47. Hussain AR, Bu R, Ahmed M, Jehan Z, Beg S, Al-Sobhi S, Al-Dayel F, Siraj AK, Uddin S, Al-Kuraya KS. Role of X-linked inhibitor of apoptosis as a prognostic marker and therapeutic target in papillary thyroid carcinoma. J Clin Endocrinol Metab. 2015; 100:E974-85. https://doi. org/10.1210/jc.2014-4356.

48. Hussain AR, Al-Jomah NA, Siraj AK, Manogaran P, AlHussein K, Abubaker J, Platanias LC, Al-Kuraya KS, Uddin S. Sanguinarine-dependent induction of apoptosis in primary effusion lymphoma cells. Cancer Res. 2007; 67:3888-97. https://doi.org/10.1158/0008-5472.CAN-063764 .

49. Ahmed M, Hussain AR, Bavi P, Ahmed SO, Al Sobhi SS, Al-Dayel F, Uddin S, Al-Kuraya KS. High prevalence of mTOR complex activity can be targeted using Torin2 in papillary thyroid carcinoma. Carcinogenesis. 2014; 35:1564-72. https://doi.org/10.1093/carcin/bgu051.

50. Hussain AR, Ahmed M, Al-Jomah NA, Khan AS, Manogaran P, Sultana M, Abubaker J, Platanias LC, AlKuraya KS, Uddin S. Curcumin suppresses constitutive activation of nuclear factor- $\kappa \mathrm{B}$ and requires functional Bax to induce apoptosis in Burkitt's lymphoma cell lines. Mol Cancer Ther. 2008; 7:3318-29. https://doi. org/10.1158/1535-7163.MCT-08-0541. 